\title{
New Technologies for Weather Accident Prevention
}

\author{
H. Paul Stough, III, ${ }^{*}$ James F. Watson, Jr., ${ }^{\dagger}$ and Taumi S. Daniels ${ }^{\ddagger}$ \\ NASA Langley Research Center, Hampton, VA 23681-2199 \\ Konstantinos S. Martzaklis ${ }^{\S}$ and Michael A. Jarrell ${ }^{* *}$ \\ NASA Glenn Research Center at Lewis Field, Cleveland, OH 44135-3191 \\ and \\ Rodney K. Bogue ${ }^{\dagger \dagger}$ \\ NASA Dryden Flight Research Center, Edwards, CA 93523-0273
}

\begin{abstract}
Weather is a causal factor in thirty percent of all aviation accidents. Many of these accidents are due to a lack of weather situation awareness by pilots in flight. Improving the strategic and tactical weather information available and its presentation to pilots in flight can enhance weather situation awareness and enable avoidance of adverse conditions. This paper presents technologies for airborne detection, dissemination and display of weather information developed by the National Aeronautics and Space Administration (NASA) in partnership with the Federal Aviation Administration (FAA), National Oceanic and Atmospheric Administration (NOAA), industry and the research community. These technologies, currently in the initial stages of implementation by industry, will provide more precise and timely knowledge of the weather and enable pilots in flight to make decisions that result in safer and more efficient operations.
\end{abstract}

\section{Nomenclature}

ACARS Aircraft Communications Addressing and Reporting System

ADS-B Automatic Dependent Surveillance Broadcast

ADWRS Airborne Doppler Weather Radar Simulator

AERI Atmospheric Emitted Radiance Interferometer

AGL Above Ground Level

AHAS Airborne Hazard Awareness System

AMDAR Aircraft Meteorological Data Relay

AOPA Aircraft Owners and Pilots Association

ASIST Aviation Safety Investment Strategy Team

ASOS Automated Surface Observing System

ATN Aeronautical Telecommunications Network

\footnotetext{
* Aerospace Engineer, Aviation Operations and Evaluation Branch, MS 152, NASA Langley Research Center, Hampton, VA 23681-2199, Associate Fellow AIAA.

$\dagger$ Aerospace Engineer, Aviation Operations and Evaluation Branch, MS 156A, NASA Langley Research Center, Hampton, VA 23681-2199.

¥Electrical Engineer, Electromagnetics and Sensors Branch, MS 473, NASA Langley Research Center, Hampton, VA 23681-2199.

$\S$ Office Chief, Aviation Safety and Security Program and Airspace Systems Program Project Office, Mail Stop 601, NASA John H. Glenn Research Center at Lewis Field, 21000 Brookpark Road, Cleveland, OH 44135-3191.

${ }^{* *}$ Electrical Engineer, Aviation Safety and Security Program and Airspace Systems Program Project Office, Mail Stop 54-6, NASA John H. Glenn Research Center at Lewis Field, 21000 Brookpark Road, Cleveland, OH 441353191.

${ }^{\dagger}$ Staff Scientist, Flight Instrumentation Branch, Mail Stop 1100, NASA Dryden Flight Research Center, Edwards, CA 93523-0273, Senior Member AIAA.
} 


\begin{tabular}{|c|c|}
\hline AvSP & Aviation Safety Program \\
\hline AvSSP & Aviation Safety and Security Program \\
\hline AWIDS & Aviation Weather Information Display Study \\
\hline AWIN & Aviation Weather Information \\
\hline AWOS & Automated Weather Observation System \\
\hline AWRP & Aviation Weather Research Program \\
\hline CIP & Current Icing Potential \\
\hline CMU & Communication Management Unit \\
\hline DAL & Delta Air Lines \\
\hline EDR & Eddy Dissipation Rate \\
\hline EFB & Electronic Flight Bag \\
\hline ES & Extended Squitter \\
\hline E-Turb & Enhanced Turbulence \\
\hline FAA & Federal Aviation Administration \\
\hline FIS-B & Flight Information Services Broadcast \\
\hline FISDL & Flight Information Services Data Link \\
\hline FSL & Forecast Systems Laboratory \\
\hline FSS & Flight Service Station \\
\hline GA & General Aviation \\
\hline GBS & Ground Based Server \\
\hline GBT & Ground Based Terminal \\
\hline GLFE & Great Lakes Fleet Experiment \\
\hline GPS & Global Positioning System \\
\hline GTRI & Georgia Tech Research Institute \\
\hline IP & Internet Protocol \\
\hline IR & Infrared \\
\hline JSAT & Joint Safety Analysis Team \\
\hline JSIT & Joint Safety Implementation Team \\
\hline Lidar & Laser Radar \\
\hline MASPS & Minimum Aviation System Performance Standards \\
\hline METAR & Aviation Routine Weather Report \\
\hline MDCRS & Meteorological Data Collection and Reporting System \\
\hline MPDS & Multiple Packet Data Service \\
\hline NASA & National Aeronautics and Space Administration \\
\hline NCAR & National Center for Atmospheric Research \\
\hline NCWF & National Convective Weather Forecast \\
\hline NEXRAD & Next Generation Radar \\
\hline NOAA & National Oceanic and Atmospheric Administration \\
\hline NTSB & National Transportation Safety Board \\
\hline NWS & National Weather Service \\
\hline PIREP & Pilot Report \\
\hline QoS & Quality of Service \\
\hline $\mathrm{RH}$ & Relative Humidity \\
\hline RMS g & Root-Mean-Square Normal Acceleration \\
\hline RTD & Resistance Temperature Detector \\
\hline RTI & Research Triangle Institute \\
\hline RUC & Rapid Update Cycle \\
\hline SIGMET & Significant Meteorological Information \\
\hline SPECI & Special Aviation Report \\
\hline TAF & Terminal Aerodrome Forecast \\
\hline TAMDAR & Tropospheric Airborne Meteorological Data Reporting \\
\hline TAPS & Turbulence Automated PIREP System \\
\hline TCP & Transport Control Protocol \\
\hline WINN & Weather Information Network \\
\hline WMO & World Meteorological Organization \\
\hline UAT & Universal Access Transceiver \\
\hline
\end{tabular}


UHF Ultra-High Frequency

VDLM2/3 Very High Frequency Data Link Mode 2 or Mode 3

VHF Very High Frequency

\section{Introduction}

In February 1997, a U.S. goal was established to reduce the fatal accident rate for aviation by $80 \%$ within ten years. A National Aeronautics and Space Administration (NASA) -sponsored Aviation Safety Investment Strategy Team (ASIST) defined research needs and the relative priority of each based on technology readiness and potential impact on safety. The ASIST participants identified weather accident prevention as a key area to be addressed and prioritized research and development investment areas. At the top of the list were data dissemination and crew/dispatch/air traffic control monitoring, presentation, and decision aids. Weather product generation, advanced aviation meteorology, and turbulence hazard solutions were also high in priority.

In April 1997, the U.S. National Aviation Weather Program Council issued a strategic plan ${ }^{1}$ for providing the improved information and tools needed to enable aviation personnel to make sound and safe decisions regarding weather hazards. This plan was followed by the definition of National Aviation Weather Initiatives ${ }^{2}$. Areas of research and development identified for NASA included multi-functional color cockpit displays of weather hazards; cockpit oriented weather products; flight information services and communications systems; quantification of hazards; and satellite-based, ground-based, and aircraft-based forward-looking technologies for hazard sensing.

In April 1998, the Federal Aviation Administration (FAA) launched its Safer Skies Focused Safety Agenda to address the U.S. national goal of reducing the fatal accident rate. Working with the general aviation (GA) industry, the FAA identified controlled flight into terrain and weather as the top-priority causes of fatal GA accidents. Onefourth to one-third of these accidents was attributed to inadequate weather decision-making. A government and industry GA Weather Joint Safety Analysis Team (JSAT) identified root causes of weather-related accidents and provided prioritized interventions to mitigate them. A GA Weather Joint Safety Implementation Team (JSIT) recommended programs to address these interventions. ${ }^{3}$ One of three principal system improvements was "Provide more accurate and precise graphical depictions of the location of weather hazard areas, through improved weather forecasts, pilot weather reports, and weather observations. Effectively deliver this information to pilots on the ground and in the air, to controllers, Flight Service Station (FSS) specialists, and dispatchers."

NASA established an Aviation Safety Program (AvSP), re-designated Aviation Safety and Security Program (AvSSP) in 2004, to develop technologies needed to help the FAA and the aviation industry meet the national safety goal. Within the AvSP, a Weather Accident Prevention Project developed technologies to reduce weather-related accidents. Working jointly with industry, NASA undertook those difficult-to-achieve and high-technical-risk initiatives that industry could not pursue alone because of a lack of facilities, technical expertise, or research capital. Over the past seven years, technologies have been developed, evaluated and implemented for cockpit presentation of graphic weather information, for look-ahead turbulence prediction, for automated airborne in-situ weather reporting, and for data linking of weather information between airplanes in flight and providers and users on the ground.

\section{Cockpit Weather Information Systems}

Huettner ${ }^{4}$ has traced the history of transport aircraft safety improvement and has identified the information technology revolution as offering the next opportunity for major reductions in accident rates. He notes that aviation weather is the one major variable that is not within the control of technology or aviation system planners. In his view, the optimal weather information system would tell pilots only what they need to know, allow them to go as close to hazardous weather as possible for maximum efficiency of flight, and yet not subject the aircraft or its passengers to conditions that would be hazardous or undesirable. The end objective would be real-time strategic and tactical weather information that could be used to separate aircraft from hazardous weather in the same way that they are separated from other aircraft today. Ritchie ${ }^{5}$ has noted that, "Deteriorating weather conditions are frequently the cause of changes in flight objectives. The pilot needs to know quickly where the weather is better and what to do to get there."

At its simplest, an aviation weather information (AWIN) system (Fig. 1) consists of weather products, a means for distributing the products to the users, and a means to present the information to the users. More than just weather information is needed by pilots to support in-flight decision making. This includes aircraft capabilities, such as the ability to fly over weather or through icing conditions; pilot capabilities, such as the ability to fly in instrument meteorological conditions; and information on flight-path-relevant terrain, obstacles, air space, and traffic. Proximity to terrain, traffic and special use airspace must be factored into the development of plans for weather avoidance. Data links are needed to exchange information between airplanes and ground stations over as 
much of the flight path as is feasible. Aircraft-to-aircraft links may be needed for timely exchange of in situ weather reports. Information from onboard sensors may be passed to ground-based weather systems for incorporation in updated forecasts and reports that can be subsequently transmitted to aircraft in flight. Datalink weather information systems are intended to provide information for long-term strategic planning and to augment onboard sensors such as weather radar and lightning detectors. Ultimately, the timeliness, accuracy and presentation of cockpit weather information need to support decisions

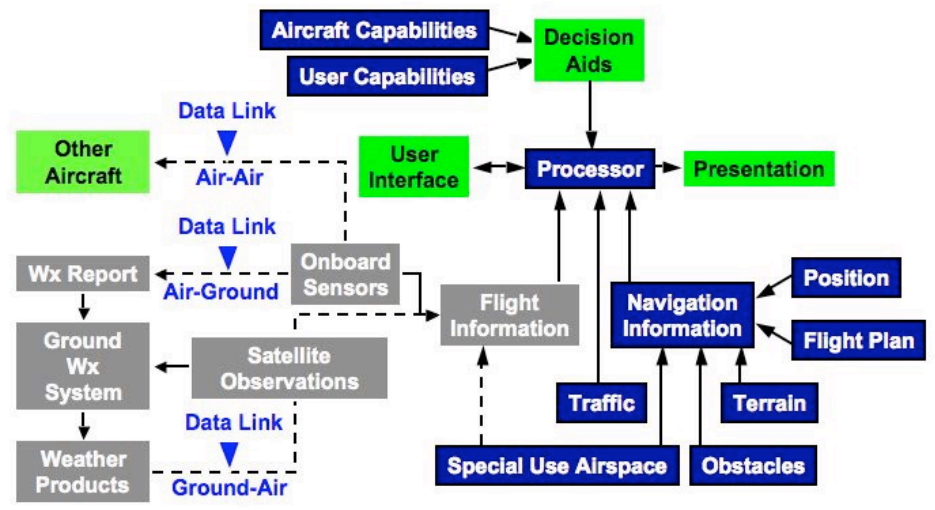
that result in safe and efficient actions.

Requirements for weather information systems reflect the needs of the various aviation communities. Transport and business aircraft usually have very capable avionics suites, have the ability to fly over or through many types of adverse weather and are flown by two professional pilots. Low-end GA airplanes and rotorcraft are typically flown by a single non-professional pilot and operate at lower altitudes in the weather. Commuter and regional aircraft share some characteristics of transports and some of GA airplanes - they have two professional pilots, but often operate at lower altitudes in the weather. Both installed and portable weather display technologies have been evaluated to meet the needs of the different user groups. NASA efforts have addressed national data-link weather information capabilities for GA, and both national and worldwide capabilities for transport aircraft.

Results of a market study ${ }^{6}$ indicated cockpit weather systems are a viable product concept with strong business cases in the transport, commuter, and business markets. In the GA and rotorcraft market segments, the business cases were sensitive to variations in cost and savings estimates; however, improved safety alone was found to be sufficient motivation for the GA and rotorcraft segments to adopt the technology. Building on the prior work of Crabill and Dash ${ }^{7}$, Georgia Tech Research Institute (GTRI) performed a study for NASA to establish weather information needs by category of user and phase of flight in support of both strategic and tactical decisions ${ }^{8}$. The study also defined aviation weather sensor capabilities and needs for hazard avoidance.

In 1998, building on knowledge gained from studies in the early 1990's of prototype data-link cockpit weather information systems for transports (Cockpit Weather Information System ${ }^{9,10}$ ) and GA aircraft (Pilot Weather Advisor ${ }^{11,12}$ ), NASA initiated cooperative research efforts with industry-led teams to "jump start" the development and implementation of AWIN systems for both transport and general aviation operators. The operational capabilities of these end-to-end systems were demonstrated through prototypes and in-service evaluations with teams led by Boeing and Honeywell for worldwide transport operations and ARNAV Systems and Honeywell-Bendix/King for U.S. national general aviation operations. These "first generation" systems utilized existing weather products reformatted for data link and display in the cockpit.

\section{A. General Aviation Systems}

In 1999, building on the NASA GA cooperative research efforts, the FAA partnered with ARNAV Systems and Honeywell-Bendix/King to create Flight Information Services Data Link (FISDL) ${ }^{13}$ systems and infrastructure that would provide data link weather nationwide in the U.S. To use the system, operators need to equip their aircraft with a VHF data radio and a color multi-function display to receive and view the information. In early 2002, FISDL achieved operational status ${ }^{14}$.

Pilots have been surveyed to characterize how they acquire and use aviation weather information. Results indicated what sources of pre-flight and in-flight weather information are used most and the desirability of various weather products for pre-flight and in-flight use. ${ }^{15} \mathrm{~A}$ cognitive task analysis has been conducted with business jet pilots ${ }^{16}$ to study how they access weather information and use it to make decisions.

The Research Triangle Institute (RTI), sponsored by NASA and the FAA, conducted experiments to investigate pilot performance using a prototype cockpit weather display in a full-mission simulator (Fig. 2). Flight scenarios impacted by adverse weather were used to assess textual and graphic weather information presentation formats and to identify potential concerns that might result from the use of these products by general aviation pilots. Initial 


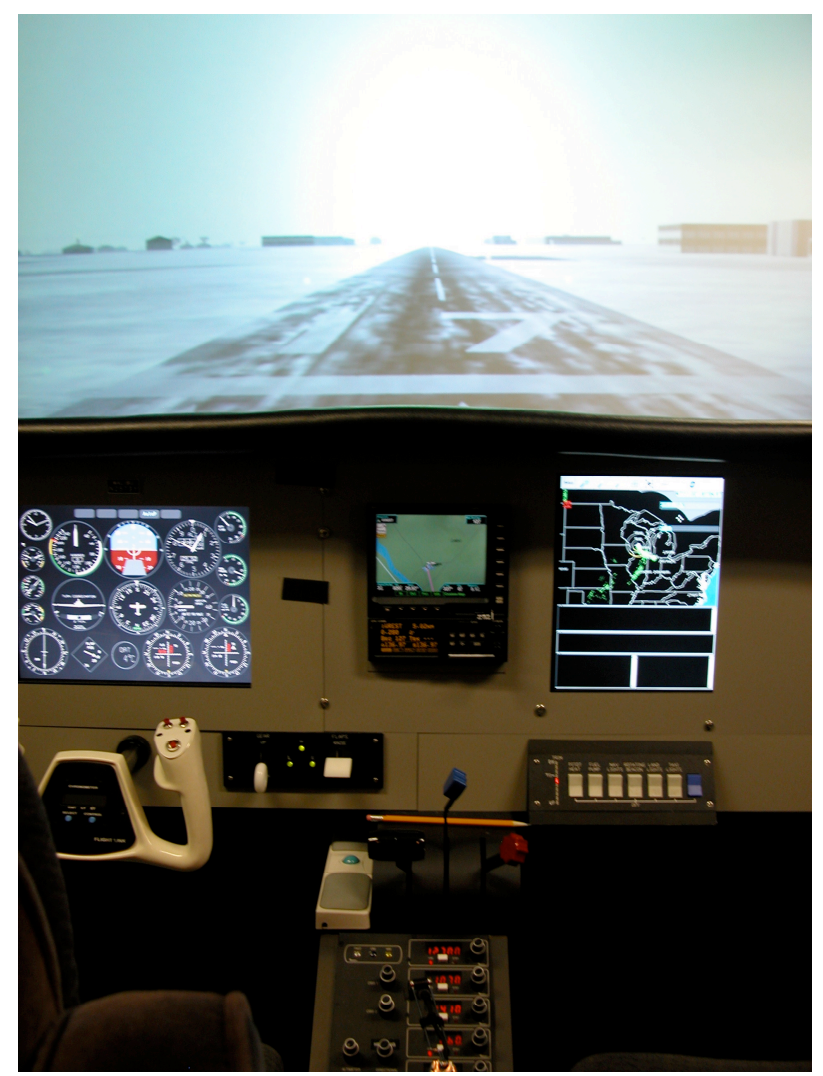

Figure 2. RTI Cockpit Research Facility with weather display on right side of instrument panel. experiments ${ }^{17-19}$ investigated early concepts for graphic presentation of weather data and the effects on pilot navigation decisions. Results of these studies supported the need to display the airplane's position as part of graphic weather depictions; to provide an indication of distance or range; and to present the age of the weather information rather than the time of creation. The resolution of the graphic depictions of data-linked next generation radar (NEXRAD) weather information was shown to affect pilot navigation decisions in adverse weather situations. The FAA Civil Aeromedical Institute conducted a pilotedsimulation study (Fig. 3) to determine how variations in resolution of displayed NEXRAD weather interact with the pilot's out-the-window view of weather. ${ }^{20}$ When their simulated cross-country flights were impacted by a band of heavy precipitation, pilots with lower resolution NEXRAD information waited longer before deciding to continue or divert. With higher resolution NEXRAD images, pilots were more likely to continue their flights with the expectation that they could fly around or between significant weather.

Sequential presentation of a series of NEXRAD images, commonly referred to as looping, has received considerable attention for indicating weather trends. In-flight use of looping is complicated by the fact that both the weather and the pilot's reference frame are moving and a pilot has limited time to look at an animated display while flying. NASA studies have explored design options and tradeoffs for in-flight weather looping products, outlined general issues and approaches for experimentally determining looping parameters that are optimal for both pilot weather situation awareness and data-link efficiency, compared weather looping with other weather trending presentations, and developed a new "aircraft looping" concept to compensate for the pilot's moving reference frame. ${ }^{21}$ An experiment has been conducted to determine the influence of the number of images per loop, total loop time, pilot viewing time, and inclusion of animated aircraft track history (aircraft looping) on optimal design of a NEXRAD looping product for the general aviation cockpit. ${ }^{22}$ The usefulness of trend information presented via looping of NEXRAD images and display of the National Convective Weather Forecast (NCWF) product has been investigated for NASA by RTI through piloted simulations. Cockpit weather displays with NEXRAD looping or NCWF provided a significant increase in situation awareness to the pilot with respect to location, proximity, and direction of movement of convective weather. However, over-reliance on the information presented by the data-link system at the expense of accessing more conventional sources of information such as FSS, Automated Weather Observation System (AWOS), and Automated Surface Observing System (ASOS), was found to offset the improved situation awareness to the

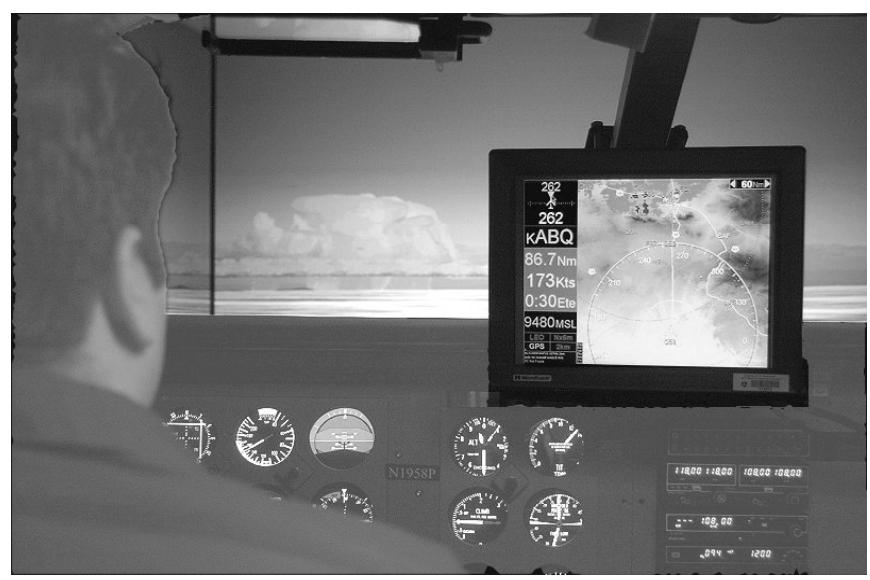

Figure 3. Weather display and out-the-window view in Advanced General Aviation Research Simulator at FAA Civil Aeromedical Institute. 
extent that decision making was no different with or without the cockpit weather display.

A prototype data-link cockpit weather information system (Fig. 4) was used in a flight test to study how well general aviation pilots detect convective weather in flight with different weather information sources. ${ }^{23-25}$ The weather information sources were seen to complement each other, such that the best in-flight convective weather situation awareness might be achieved when pilots use all three weather sources (radio voice communication, outthe-window view, and data-link display) together.

A flight experiment was conducted to study the effects of the location in the cockpit of a graphic weather information display (Fig. 5) on the ability of general aviation pilots to access weather information while flying in visual and instrument meteorological conditions. ${ }^{26}$ Three different display locations - panel, yoke and kneeboard were studied with a display mounted in the center of the instrument panel being most preferred, although all were acceptable. Overall, pilots were able to access weather information much faster via the data-link system than via voice transmissions from ground stations such as ASOS.

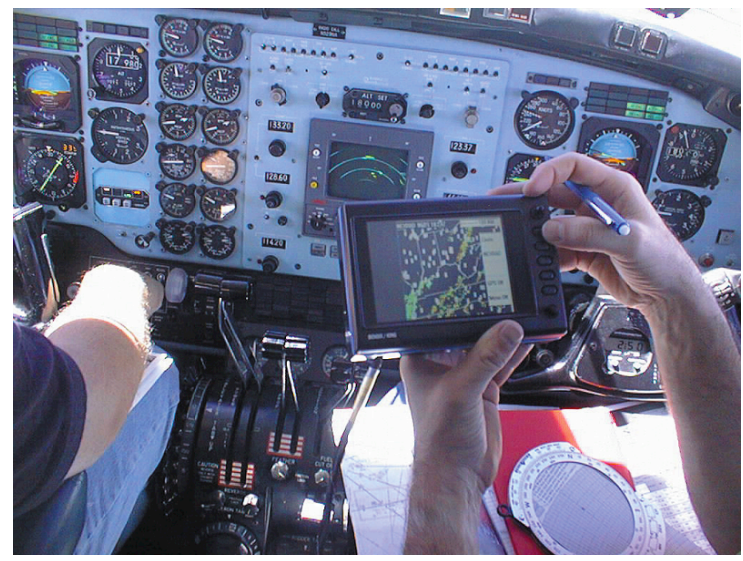

Figure 4. Portable AWIN display connected to NASA B-80 via a tether.

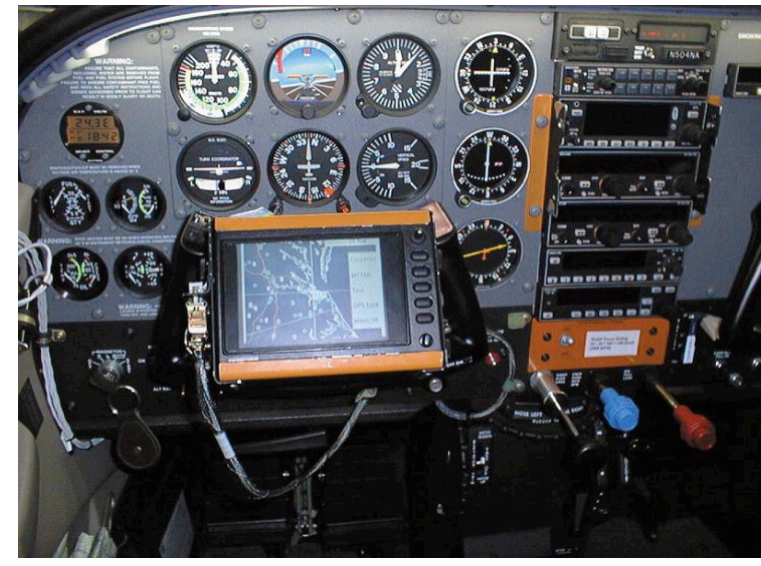

Figure 5. Prototype AWIN display mounted to the yoke in NASA C-206.

\section{B. Commercial Transport Systems}

Honeywell International, Inc., in a joint effort with NASA, developed a Weather Information Network (WINN) capable of providing graphical weather information to the cockpit of commercial and business aircraft flying anywhere in the world. The network included airborne displays, airborne and ground-based servers, and multiple providers of weather products and data-link services. An open architecture was adopted to accommodate any kind of data-link technology. Both a satellite-based link and a terrestrial $\mathrm{VHF} / \mathrm{UHF}$ telephone link were evaluated. Several different types of weather information could be overlaid or viewed individually. Evaluations were performed with systems installed in a Citation business jet, a United Airlines B-777 full flight simulator, NASA's B-757 transport research airplane (Fig. 6), and a United Air Lines Airbus A320 (Fig. 7). During the winter of 2001, United Air Lines conducted over 40 inservice evaluation flights with the WINN system incorporated in a prototype electronic flight bag (EFB). Aircraft position information was provided by a portable global positioning system (GPS). Weather products were delivered to the airplane via a GTE Airphone and included airport observations (METARs), terminal area forecasts (TAFs), ground weather radar reflectivity (NEXRAD), turbulence, significant weather cautions (graphic SIGMETs), and satellite cloud images. Information was displayed on a Fujitsu Pen Tablet. An

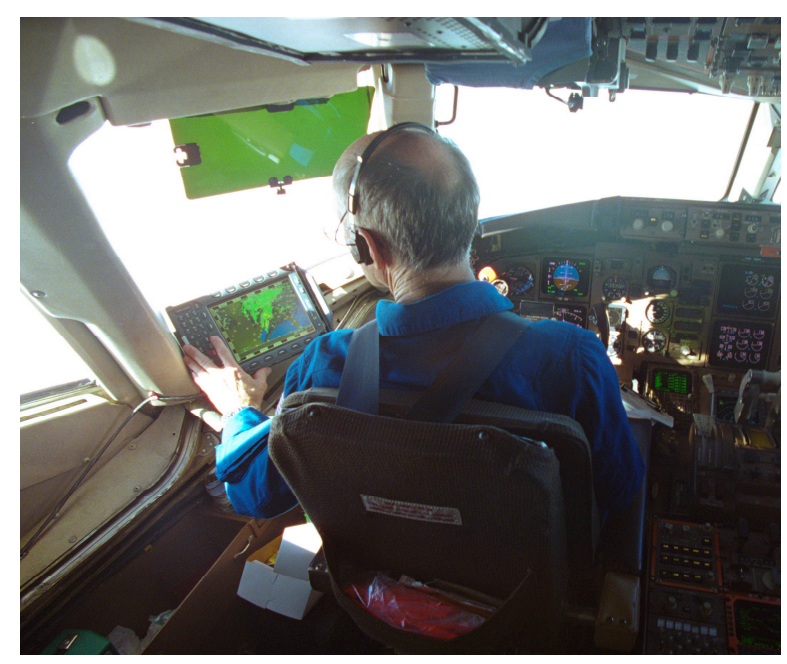

Figure 6. WINN display in NASA B-757. 


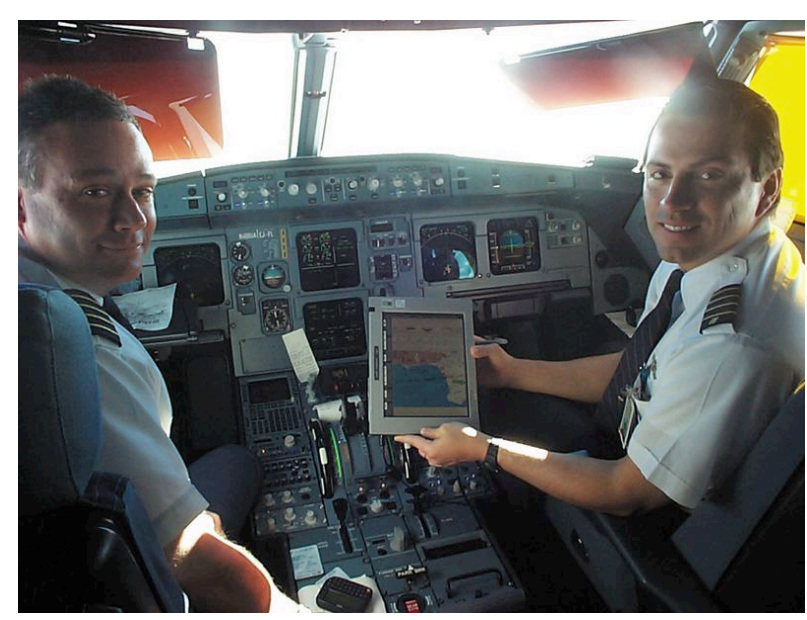

Figure 7. WINN display on tablet computer in United Air Lines A320.

help the pilot search the information sources available, identify trends and changes affecting his or her flight, and make timely decisions to avoid hazardous weather.

Working with GTRI and Rockwell Collins, NASA has developed a prototype cockpit weather information system with the capability to combine information from both on-board sensors and data-links and to display graphical and textual weather information to the pilots. This Airborne Hazard Awareness System (AHAS) can automatically parse text and weather data, convert it to graphics, evaluate both tactical and strategic hazards in the weather data stream and provide alerts to pilots. Weather products include visibility, ceiling, winds, gusts, precipitation, thunderstorm proximity and severity, hail, icing and turbulence. Satellite echo top data are correlated with NEXRAD attribute data to associate storm tops with storms in the NEXRAD data. Hazards assessed include proximity of SIGMETs en route, winds aloft en route, projected thunderstorm intercept, remarks from METAR stations along the flight plan, pilot reports (PIREPs) within a corridor of the flight plan, and crosswinds, ceiling and visibility at the destination airport. A sample tactical display is shown in Fig 8.; a sample strategic display is shown in Fig. 9. The components of AHAS resulted from technologies developed through Enhanced Weather Radar ${ }^{28}$ and Advanced Weather Awareness and Reporting Enhancements ${ }^{29}$ cooperative research between NASA and Rockwell Science Center (now Rockwell Scientific).

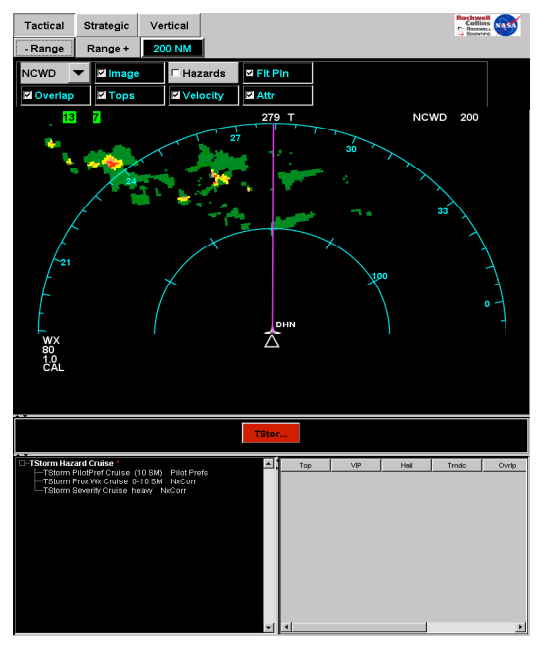

Figure 8. AHAS tactical display with combined presentation of onboard radar and data-linked NEXRAD.

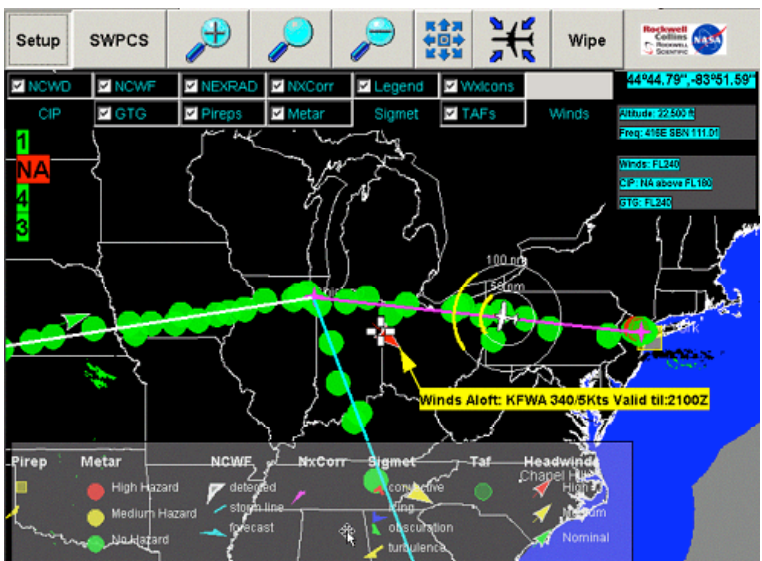

Figure 9. AHAS strategic interface. 
An Aviation Weather Information Display Study (AWIDS) conducted by GTRI, Rockwell Collins and the University of Iowa used the AHAS to investigate the advantages of integrating the display of onboard weather radar with data-linked NEXRAD. ${ }^{30}$ Weather radar information close ahead of the airplane combined with track-up data-linked NEXRAD imagery was compared to separate displays of onboard weather radar and north-up or track-up NEXRAD. Fourteen airline and business pilots participated in a part-task simulation using the B-737-800 simulator at the University of Iowa's Operator Performance Laboratory (Fig. 10). The subjects were found to be more likely to make correct deviation decisions with the integrated display. Greater situation awareness, lower workload, and ability to make weather decisions sooner were also attributed to the integrated display. Usefulness of the integrated display for avoidance of adverse weather was linked to the inclusion of such things as cloud tops in the NEXRAD information.

In addition to integration of weather information sources, NASA-sponsored studies have investigated flight crew trust of the displayed weather information and the way that flight crews react as a team to displays of impending adverse weather. A simulation experiment (Fig. 11) conducted by Old Dominion University ${ }^{31}$ investigated the influence of agreement or disagreement between onboard weather radar and data-linked NEXRAD displays, distance to adverse weather, and pilot flying on flight crew situation awareness, workload, and deviation decisions. Fifteen pilot-copilot crews flew a simulated route while reacting to weather events presented in two graphical formats on a separate display. Results indicated that crews trusted the onboard weather radar more than the datalinked weather information. When both systems agreed, the crews trust of the data-linked weather display

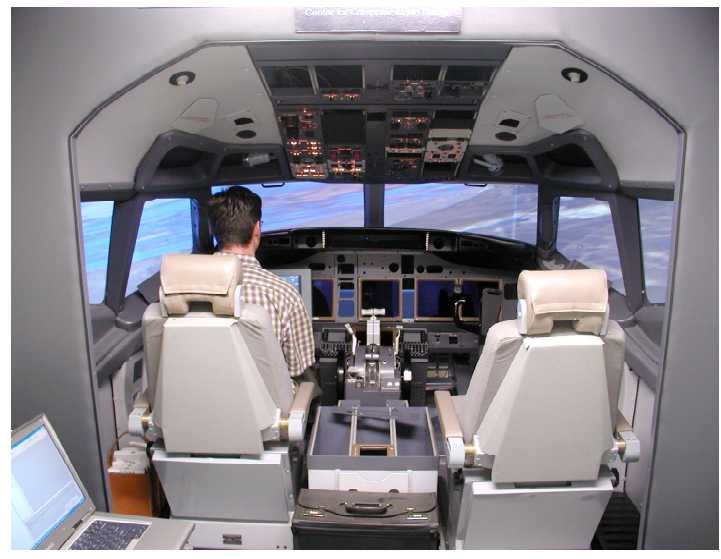

Figure 10. University of Iowa B-737-800 simulator used for Aviation Weather Information Display Study (AWIDS).

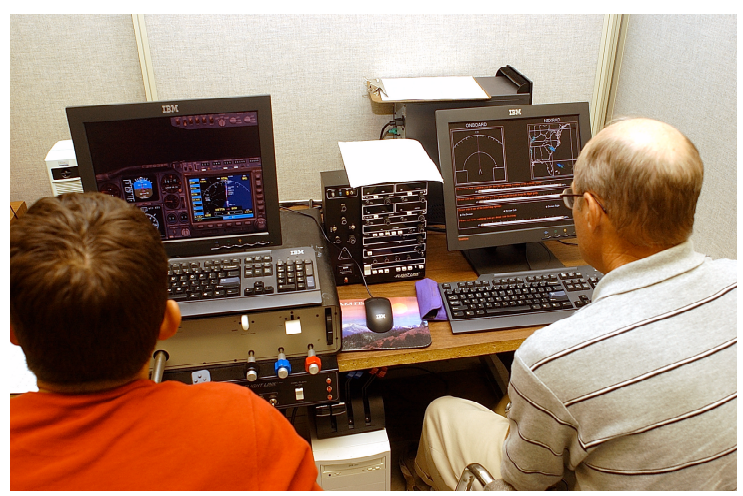

Figure 11. Simulation set up at Old Dominion University for team decision-making experiment.

increased. When the onboard and NEXRAD displays did not agree, the crews trusted the onboard radar more, but still used the NEXRAD to augment their overall situation awareness. Crews were more likely to make correct deviation decisions when the NEXRAD system depicted the impending adverse weather.

\section{Implementation}

Implementation of cockpit weather information systems has been supported by development of related guidelines and standards. The RTCA has published Minimum Aviation System Performance Standards (MASPS) for Flight Information Services-Broadcast (FIS-B) Data Link ${ }^{32}$ for systems providing non-control advisory information used by pilots to improve safety and efficiency of operations in the U.S. national air space. These standards include functional and performance requirements, procedures for performance verification, and guidelines for information display. The standards incorporate knowledge gained from NASA and industry research and development and can be used by the FAA Flight Standards and Aircraft Certification Services to develop criteria for approval of FIS-B airborne equipment. Results have also been incorporated in FIS-B guidance included in FAA Advisory Circulars ${ }^{33}$ and the Aeronautical Information Manual. ${ }^{34}$ The FAA has also issued guidance on EFBs, including portable, attached, and installed devices. ${ }^{35}$

In the U.S., data-link cockpit weather information systems have now become a commercial off-the-shelf item, especially for general aviation. Numerous companies have formed alliances to combine weather information, communications, and display technologies into systems to deliver weather information to the cockpit of general aviation airplanes. A variety of display devices and information delivery architectures are being employed to address the varied needs of GA operators. The June 2005 issue of AOPA Pilot magazine ${ }^{36}$ noted "Datalink came to the handheld market a little more quickly than to panel mounts - simply because it's easier to bring the uncertified 
product into the cockpit. And the lure of graphics in the cockpit coupled with a reasonable cost to equip with a basic system has driven pilots to make the purchase of a datalink system their first major hardware buy since they invested in a handheld com or GPS." The AOPA Pilot article goes on to note that one manufacturer of both portable and panel-mount data-link, weather information systems has sold 2,000 units in less than three years. Not long after this article appeared, a handheld GPS receiver with color moving-map display and integral satellite-broadcast data-link weather display became commercially available. The FAA recently began implementation of a U.S. national Universal Access Transceiver (UAT) network for provision of traffic and flight operational information, including weather, data-linked to the cockpit of equipped aircraft. ${ }^{37}$ Initial weather products include text METARs, TAFs, and Special Aviation Reports (SPECIs) and graphic NEXRAD precipitation maps. Despite the challenging financial conditions confronting U.S. airlines, one major carrier has indicated plans to begin equipping its fleet with EFBs showing data-link weather information by the end of 2005. Operational benefits of strategic avoidance of convective weather are a key justification for the equipage.

\section{Turbulence Prediction and Warning Systems}

Aircraft encounters with atmospheric turbulence are the leading cause of accidents and injuries to transport aircraft passengers and crew. The overall operational cost to the airline industry is estimated to be about $\$ 750$ million/year. ${ }^{38}$ NASA created a team to increase understanding of both the turbulence phenomena and the effects of turbulence on aircraft, and to develop technologies to detect turbulence ahead of aircraft in flight and mitigate the effects on aircraft passengers.

The technologies developed by NASA include: 1) turbulence modeling and simulation studies to understand the hazard imposed for commercial transport aircraft, 2) airborne systems such as radar and lidar for predicting turbulence ahead of the aircraft and displaying the level of hazard to the airplane, and 3) the automated reporting of the hazard level experienced by the aircraft when turbulence is encountered. These technologies have formed an airborne centric concept to provide turbulence information to flight crews with sufficient accuracy and timeliness to enable appropriate actions to be taken to prevent human injuries and aircraft damage.

According to National Transportation Safety Board (NTSB) accident records, cabin occupants who are seated with their seat belts securely fastened are rarely injured in turbulence encounters. A critical issue in avoiding turbulence injuries is providing a reliable warning in sufficient time for cabin occupants to be seated and belted prior to the encounter. In October 2002, an Aircraft Cabin Turbulence Warning Experiment $^{39}$ was conducted to establish the time required to seat the vast majority of cabin occupants under the most difficult conditions. The experiment utilized the FAA Civil Aeromedical Institute's fullscale B-747 wide-body aircraft simulator (Fig. 12), human passenger subjects, and active line-qualified flight attendants from three separate airlines. Results of the experiment indicated that if the pilot receives a reliable turbulence alert, and announces a warning within 10 seconds, over $95 \%$ of the passengers and flight attendants can be securely seated within 110 seconds, thereby removing them from the risk of injury caused by a turbulence encounter.

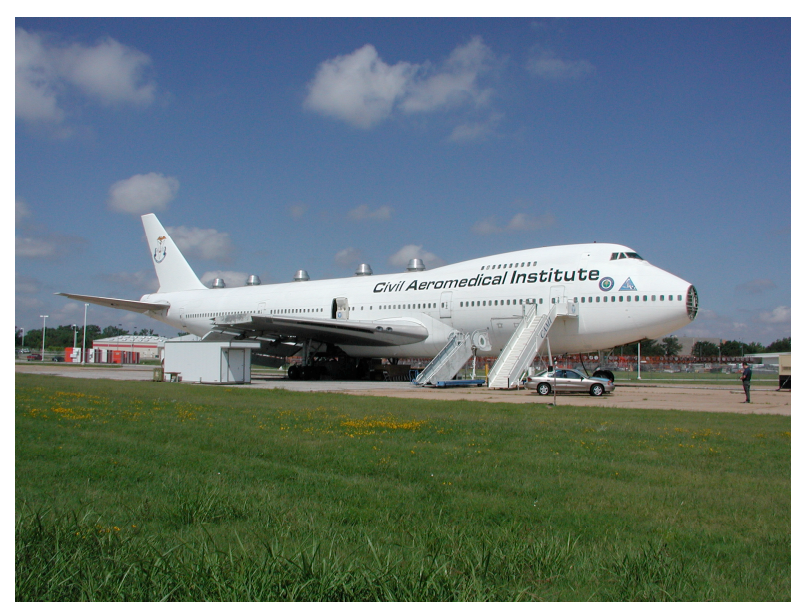

Figure 12. FAA Civil Aeromedical Institute B-747 wide-body aircraft simulator.

Working with the FAA, avionics manufacturers, airline operators, and the weather research community, NASA has significantly enhanced the capabilities of existing airborne weather radars to detect turbulence and display the severity level up to 25 nautical miles ahead of commercial jet transports for altitudes greater than $2000 \mathrm{ft}$ above ground level (AGL). The aircraft turbulence hazard metric is an acceleration-based intensity index dependent upon the specific aircraft type and flight conditions. Automated, event-driven turbulence encounter reporting using the acceleration-based hazard metric has been developed. Turbulence encountered in flight can be automatically communicated to ground stations and other aircraft as a root-mean-square normal acceleration (RMS g) value that can be converted to an airplane unique hazard level via the hazard index. These capabilities have progressed from research aircraft and prototype systems to yearlong in-service evaluations with Delta Air Lines concluding in September 2005. 


\section{A. Enhanced Turbulence Radar}

NASA teamed with AeroTech Research, NCAR, RTI, and Rockwell Collins for the development and validation of airborne turbulence hazard detection capabilities. About $75 \%$ of turbulence encounters were found to occur in proximity of significant convective activity, even though the aircraft may have been "out of cloud." ${ }^{, 40}$ For altitudes above $2000 \mathrm{ft}$ AGL, existing airborne wind shear radars possess significant signal processing capabilities that can be utilized to enable turbulence detection. From this it was concluded that the reflectivity detection capability of current airborne radars, while setting a floor for convectively-induced turbulence, could provide a greater than $50 \%$ increase in look-ahead turbulence prediction capabilities. Analyses, studies and simulations led to development of a research airborne radar unit with initial turbulence detection algorithms that was flight tested on NASA's B-757 in late $2001 .^{41,42}$ Atmospheric conditions of past turbulence encounters that resulted in passenger or crew injuries were modeled and served as validation cases for the prediction technology. ${ }^{43,44}$

Infrared radar (lidar) uses reflected energy from natural aerosols to detect turbulence in much the same way that conventional weather radar uses reflection from atmospheric moisture to detect the presence of turbulence and dangerous weather conditions. This technology has the potential to augment conventional weather radar to detect dangerous turbulence that occurs in clear air that is devoid of moisture. Beginning in 1998, a series of flight tests were conducted of a prototype infrared weather radar. ${ }^{45,46}$ Although its range of detection was limited due to low pulse energy, this system was able to reliably detect turbulence at a range of about 1.2 miles, and up to 8 miles in optimal atmospheric conditions. In over 100 hours of flight testing, there was no case of an undetected turbulence encounter. Practical application to commercial aircraft will require system improvements to increase efficiency, increase pulse energy and reduce size.

Studies of the commercial transport fleet indicated that the same atmospheric turbulence will produce widely varying aircraft response depending upon aircraft type, weight, configuration, and flight conditions. As NASA has a B-757 research aircraft and there were several past turbulence encounters with injuries involving this type aircraft, atmospheric conditions were modeled and flight simulators were used to determine B-757 response to various turbulence encounters. This analysis concluded that a turbulence encounter hazard severity level based upon RMS $g$ could be correlated to items going weightless in the cabin, which is an indicator of potential passenger injury. The range of flight capabilities (weight, altitude, airspeed) of the B-757 necessitated that a hazard table would be needed to accurately determine the hazard severity level associated with the radar-derived parameter of atmospheric turbulence, spectral width. Further studies using a B-747-400 simulator concluded that hazard tables would need to be developed for each major aircraft type. During the spring of 2002, the NASA B-757 was used to test an airborne radar with a signal processor incorporating a turbulence algorithm and internal radar parameter data logging capability. The research radar was evaluated in the vicinity of convective activity that produced atmospheric turbulence. The research radar unit contained special software for statistically predicting the atmospheric spectral width (deviation in Doppler velocities) using multiple radar antenna scans, computing the 757's anticipated response to the encounter using the hazard tables, and generating a near-real-time hazard level display at an onboard researcher console. The research radar console and a close-up of the display are shown during a turbulence encounter in Fig. 13 and Fig 14, respectively. For validation of this look-ahead turbulence hazard prediction capability, an aircraft response measurement software package was developed using the acceleration at the

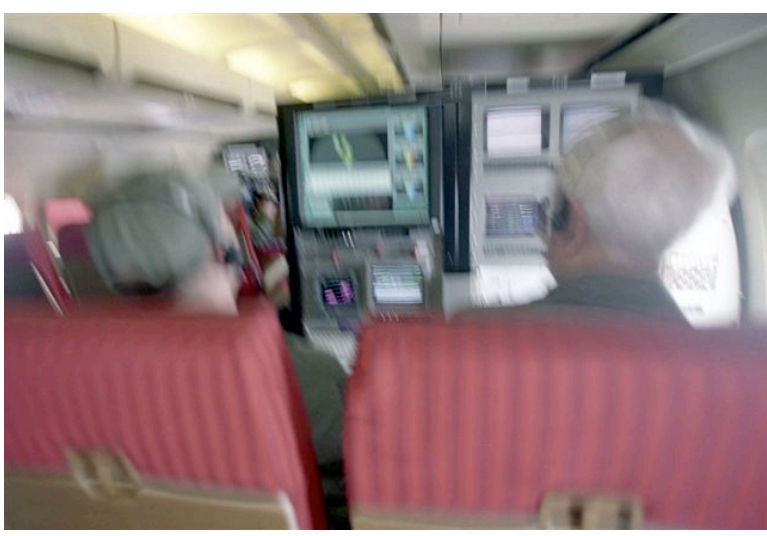

Figure 13. Research radar console on NASA B-757 shown during a turbulence encounter.

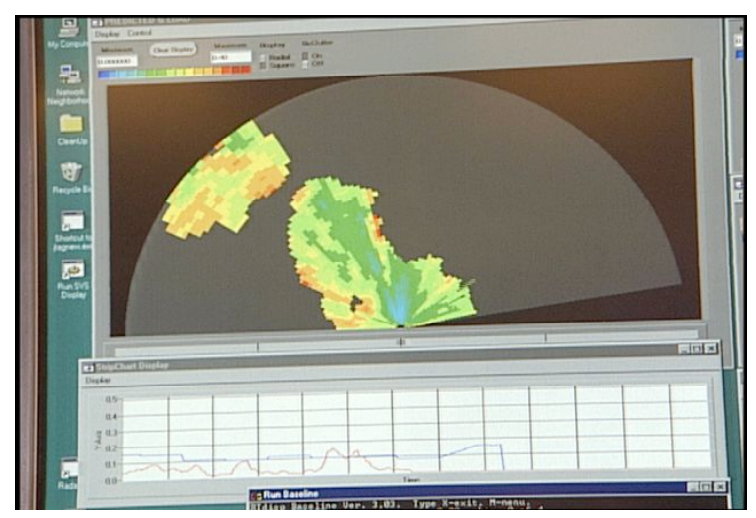

Figure 14. Close-up view of turbulence research radar display at researcher's console onboard NASA B-757. 
airplane's center of gravity and other aircraft flight parameters to compute "truth RMS g". Subsequently, these particular software algorithms became the basis for an automated turbulence encounter reporting system.

The spring 2002 flight tests, including 55 turbulence events, validated the research concepts and indicated that moderate-tosevere turbulence hazards to the aircraft could be predicted with $80 \%$ confidence and at least a 90 second warning time could be provided for radar reflectivity levels above $15 \mathrm{dBz} .{ }^{47}$ Hazard severity thresholds were determined that reflect when passengers should be seated, seatbelts should be buckled, and cabin equipment should be secured. Aircraft response in RMS g's over time for a turbulence encounter is presented in Fig. 15. A postprocessed display of a turbulence encounter indicating a 96 second lookahead capability is presented in Fig. 16. It has been estimated that implementation of these capabilities could provide a fifty percent reduction in turbulence induced injuries to passengers and flight attendants. $^{39,48}$

A set of aircraft specific hazard tables has been developed using aircraft flight simulators for eight different commercial jet transports. ${ }^{49}$ This enables potential radar manufacturers and turbulence algorithm developers to relate the spectral width radar parameter to actual aircraft response. Ease of retrofit of the enhanced turbulence mode to existing airborne wind-shear radars is dependent upon availability of a databus and autoscan capability. Turbulence hazard assessment requires use of several flight parameters, such as weight, altitude and airspeed, whose access is facilitated if the airplane has a data-bus. Figure 17 shows the normalized loads for eight transport aircraft types and the error range over normal flight attributes.

During the latter half of 2003, the radar development team partnered with Delta Air Lines (DAL) for a two-year in-service evaluation. The objective of the in-service evaluation was to develop a pre-production prototype airborne radar using the latest commercial unit with the new turbulence hazard prediction algorithms, to provide a cockpit display, and to evaluate performance on a revenue airplane. A Rockwell Collins WXR-2100 commercial airborne weather radar, that already had automated antenna multi-scan capability, was used. The prototype unit replaced the existing unit on a DAL B-737-800 airplane. The radar was modified with a flash memory data logger, updated algorithms for spectral width radar signal processing, a B-737-800 turbulence hazard table algorithm, data bus flight parameter interface, and color turbulence display capability. The prototype radar unit received FAA certification and was installed on a DAL airplane in 2004. The prototype Enhanced-Turbulence (E-Turb) Radar provides turbulence hazard prediction capability extending at least $25 \mathrm{~nm}$ ahead of the aircraft. Two levels of magenta are used on the

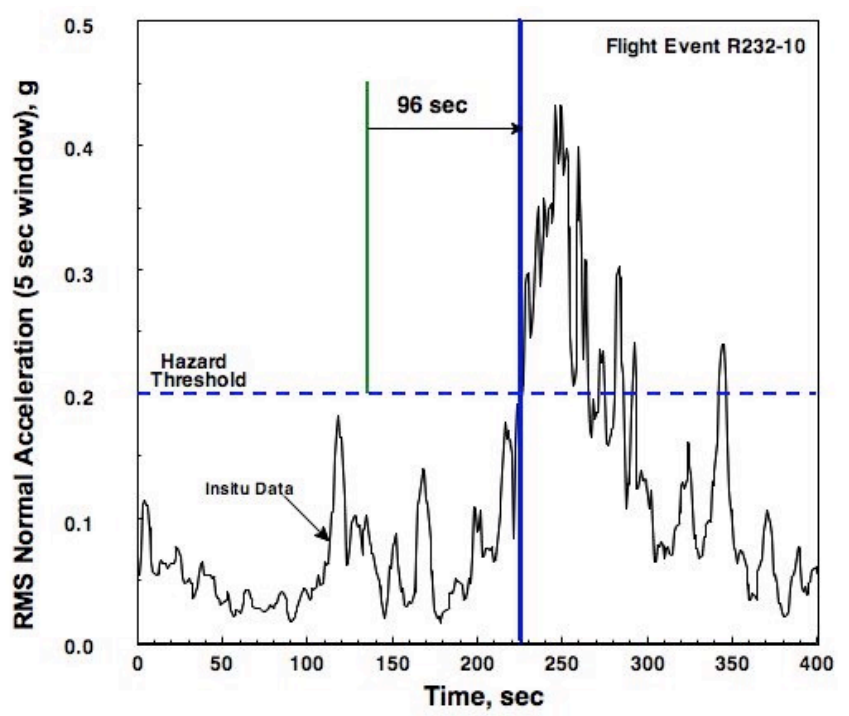

Figure 15. NASA B-757 response to a turbulence encounter.

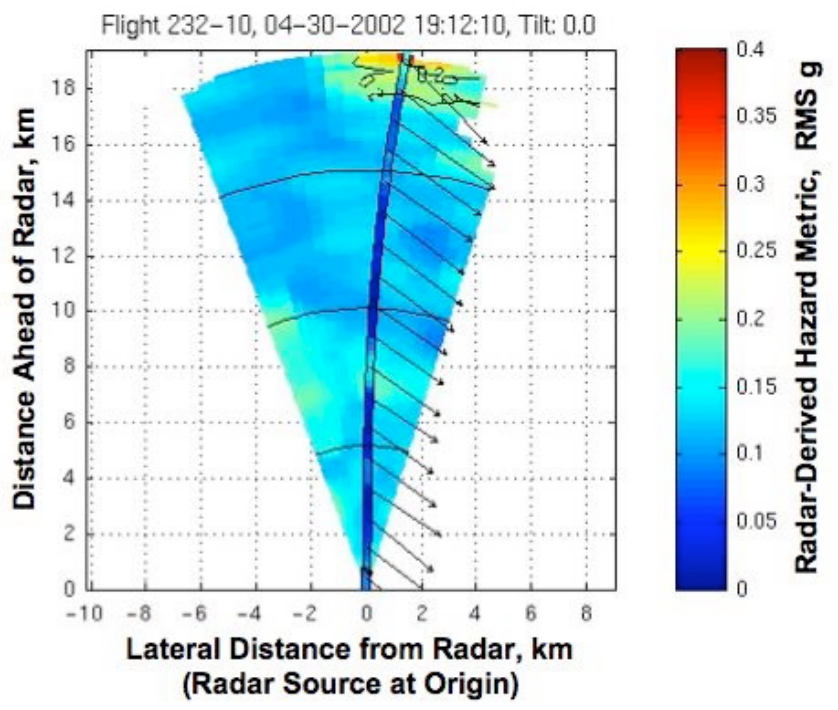

Figure 16. E-Turb Radar hazard prediction corresponding to Figure 15 at 96 sec before hazard threshold exceedance. 

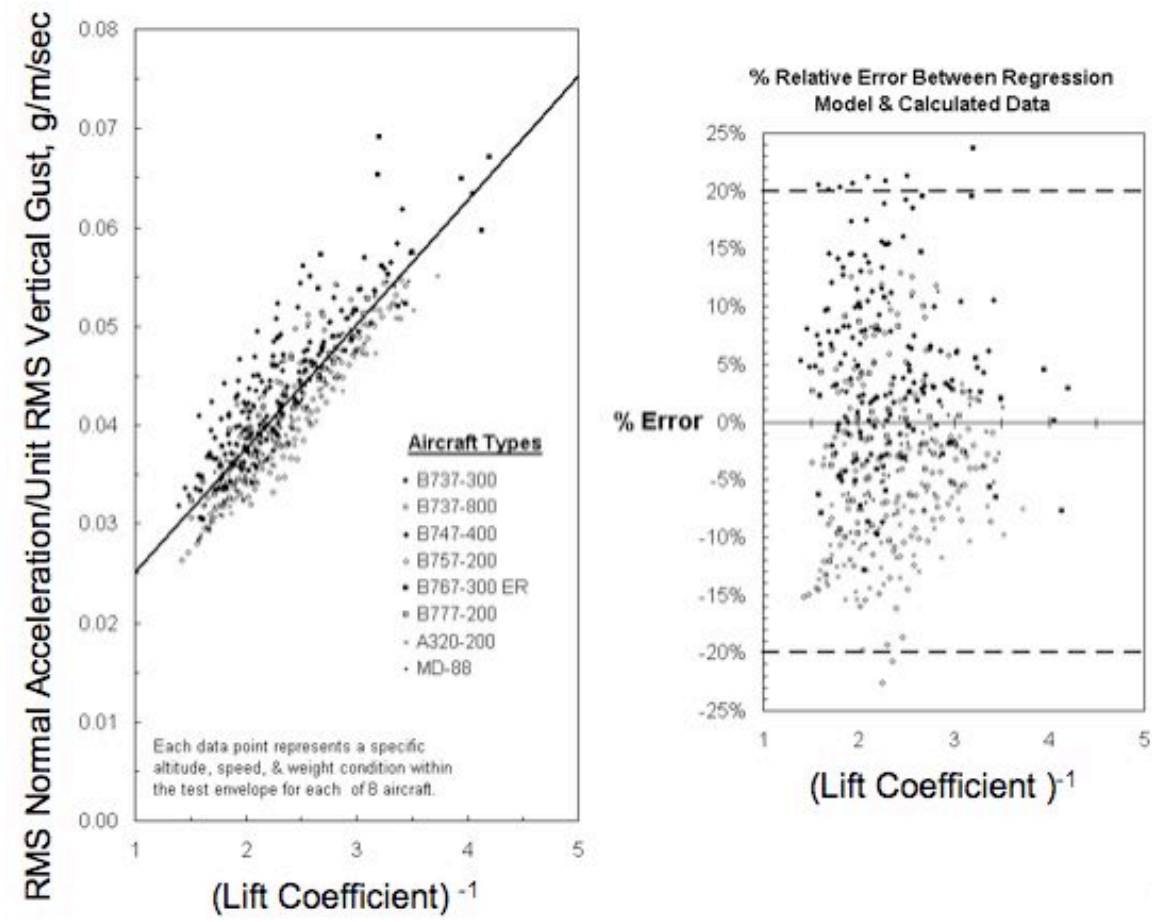

Figure 17. Normalized loads for eight transport aircraft types and the error range over normal flight attributes. Turbulence scale $=500 \mathrm{~m}$.

radar display to indicate turbulence hazards - one based upon "ride quality," and one based upon need to "secure the cabin." These can be related to the traditional "light" and "moderate to severe" turbulence designations. Crew reports indicate that the accuracy and consistency of the encounter predictions, and aircraft response when turbulence could not be avoided, have resulted in confidence in the E-Turb mode. This in-service evaluation extends through September 2005. Figure 18 shows the E-Turb Radar configuration used for the DAL 737-800 in-service evaluation. Figure 19 shows an actual cockpit radar display of the two levels (speckle and solid) of magenta. The picture illustrates the ability to predict turbulence in low reflectivity (black and green on the display indicate regions of low reflectivity).

Through June 2005, 416 events have been analyzed from data downloaded from the E-Turb Radar aboard the DAL 737-800. Of these, 46 events occurred with no radar display of predicted turbulence, but the aircraft experienced turbulence; 139 events occurred where the radar displayed regions of turbulence, but the aircraft did not

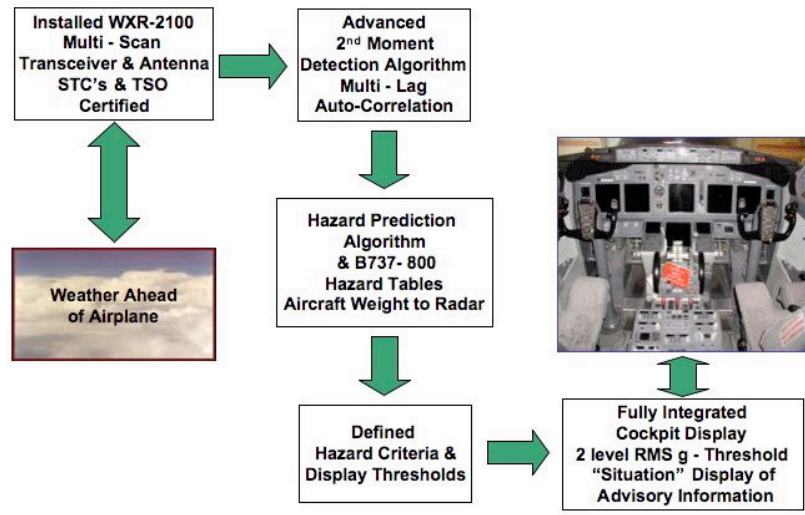

Figure 18. E-Turb Radar configuration used for inservice evaluation.

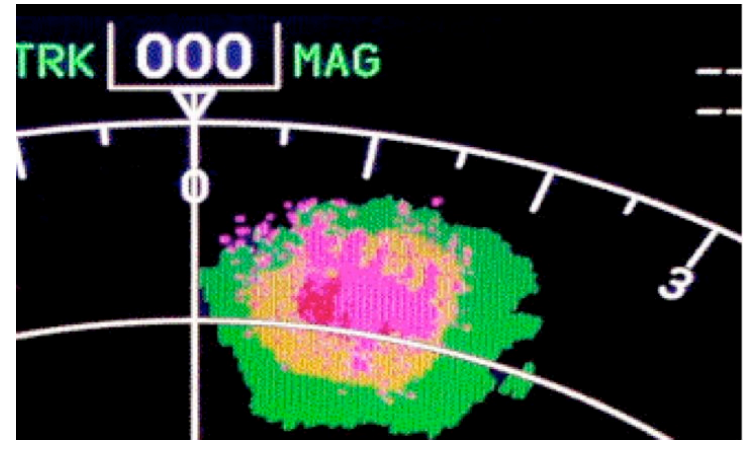

Figure 19. Cockpit radar display of turbulence prediction from Enhanced-Turbulence Radar. 
penetrate the region (often maneuvered away); and 231 events occurred where the aircraft displayed turbulence and penetrated the region. Initial analysis of predicted accelerations and measured accelerations for these 231 events indicate that the E-Turb Radar unit produces reliable predictions within a $95 \%$ confidence interval. Figure 20 shows the correlation of loads to estimated radar attributes for a total of 335 turbulence encounters from historical accident cases, all the NASA B-757 flight tests, and 231 encounters from the DAL in-service evaluation.

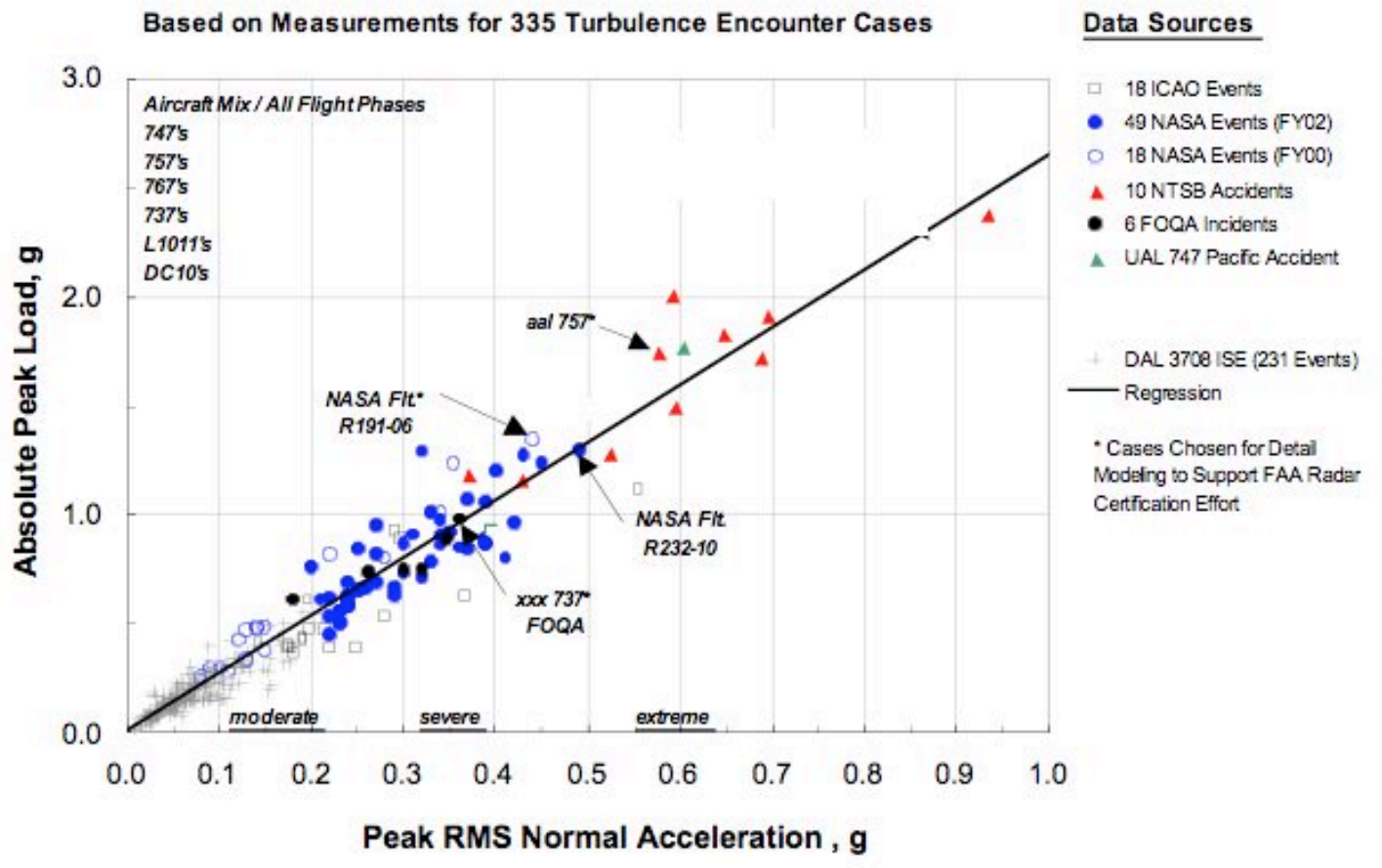

Estimated from radar observables for Turbulence Prediction and Warning System concept

Figure 20. Correlation of loads to estimated radar attributes.

\section{B. Turbulence Automated PIREP System}

Currently, turbulence encounter reporting is primarily dependant upon pilot reports (PIREPs) passed from the cockpit to controllers, briefers and dispatchers via voice communications. These "ride reports," however, do not fulfill the needs of airline operations. A capability is desired that produces consistent, accurate, and timely reports of the location and severity level of aircraft encountered turbulence. These reports would become part of the turbulence related information used by airline operations including flight planning and dispatch, maintenance, and meteorological centers.

An automated process has been developed to fulfill the need for accurate and timely turbulence encounter reports. The airplane turbulence response algorithms developed for evaluating the E-Turb Radar performance provided a means to convert airplane response into an RMS g level that could be communicated to other aircraft and, using a response algorithm for that airplane, converted into a relevant hazard level specific to the receiving airplane. These algorithms or "hazard tables" provide the basis for an automated turbulence encounter reporting system. Thresholds were established for triggering automated turbulence reports, and the resulting information was packaged into a message for automatic transmission to other airplanes aloft and to ground stations. From the ground station, these turbulence encounter reports can be routed to the corresponding flight operations function with sufficient timeliness to benefit turbulence avoidance decisions. This capability, designated Turbulence Automated PIREP System (TAPS), provides timely and accurate reporting of turbulence encounters, and directly relates to the hazard metrics used to display turbulence detected by the enhanced turbulence mode radar. In the spring of 2002, TAPS capability was demonstrated by transmitting turbulence encounter generated information via a satellite communication research data link from the NASA B-757 to a ground station at the NASA Glenn Research Center. 
Figure 21 shows the NASA B-757 TAPS research console. Figure 22 shows a time history of a turbulence encounter using the TAPS algorithm and the threshold levels for transmission from the aircraft.

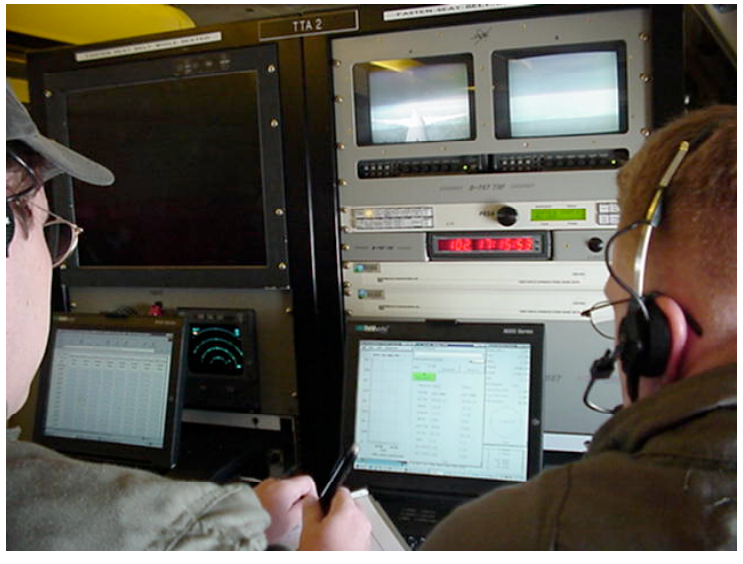

Figure 21. TAPS research console on NASA B757.

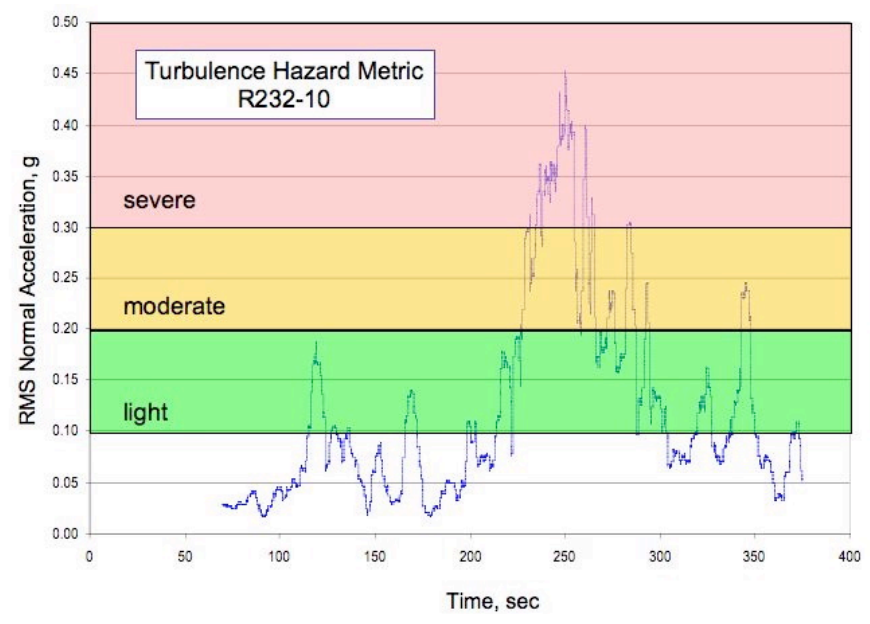

Figure 22. Time history of turbulence encounter using the TAPS algorithm and threshold levels for transmission from the aircraft.

Beginning in 2004, an in-service evaluation of TAPS was undertaken in partnership with DAL. The TAPS reports are collected and stored at the airline operations center and are formulated for use in flight planning and dispatch, and in aircraft inspection and maintenance. The initial TAPS equipped DAL aircraft began transmitting reports in July 2004. The entire DAL fleet of 71 B-737-800 aircraft was TAPS enabled and sending reports by September 2004. One of these airplanes is equipped with the E-Turb Radar; therefore, for this airplane, TAPS is a significant aspect of radar performance validation for turbulence encounter and response prediction. During 2005, the TAPS-equipped fleet has been expanded to include some DAL B-767-300 and -400 aircraft that typically fly oceanic routes.

WebASD, the display system utilized by the DAL dispatchers, was modified to provide turbulence encounter flight information within its existing flight following capabilities. TAPS reports can be displayed for up to the last twelve-hour period. These reports can be related to the traditional "light," "moderate," and "severe" turbulence designations. All dispatchers within the DAL flight operations center (about 130) are participating in the evaluation of the system, which began in June 2005 and extends through September 2005.

Through June 2005, over 13,000 TAPS reports have been logged and analyzed. Dispatcher feedback has been highly supportive of the accuracy and consistency of TAPS reporting. Inspection and maintenance crews have also been highly supportive of TAPS reporting because they can determine inspection needs right after significant encounters and schedule necessary resources at the airplane's destination site. Figure 23 shows a system configuration of the TAPS for the in-service evaluation. Figure 24 shows an actual WebASD display for a dispatch terminal.

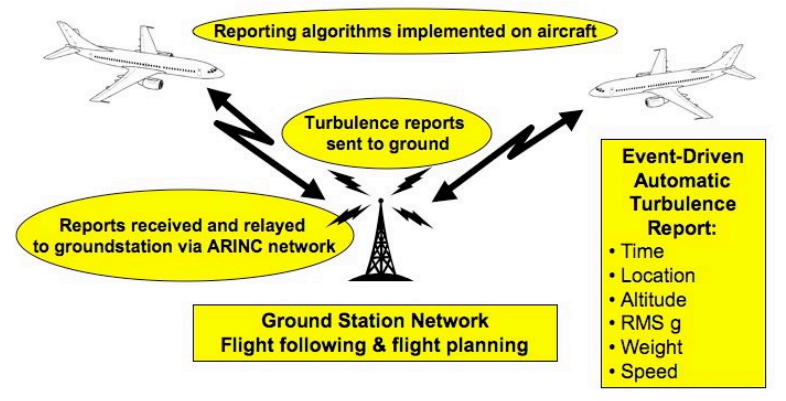

Figure 23. TAPS configuration for in-service evaluation.

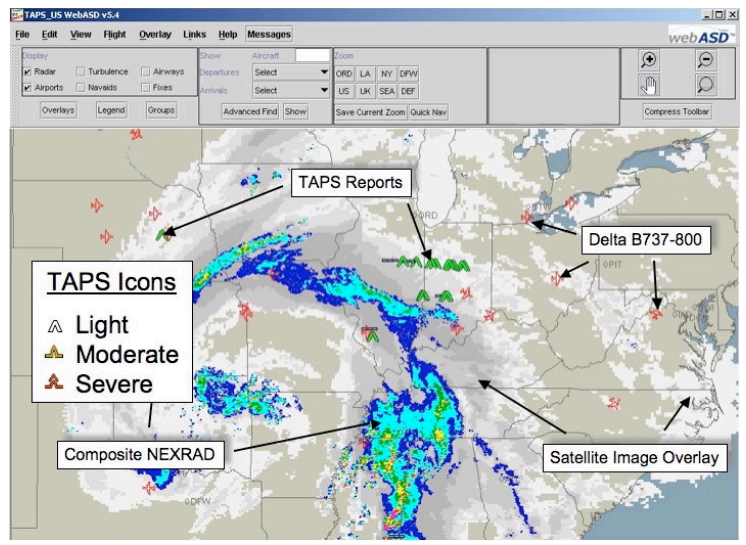

Figure 24. WebASD TAPS display. 


\section{Implementation}

A NASA-FAA-Industry Turbulence Certification Team was formed in 2000 to address FAA certification of turbulence prediction radar and to work issues in concert with the technology development. Because certification by flight testing was deemed very costly and time consuming, development of a certification-via-simulation process was undertaken. During the latter half of 2003, several Turbulence Certification Workshops were conducted by NASA with avionics manufacturers and FAA certification personnel to develop a process and tools for certifying airborne turbulence detection systems via a simulation process. Six elements were identified that would be integrated to comprise the process: (1) turbulence events/scenarios; (2) radar simulation; (3) radar algorithms; (4) aircraft specific test criteria; (5) aircraft "truth" fields; and (6) comparative analysis and statistics.

These six activities have resulted in implementation of a baseline capability. Four atmospheric data sets have been developed that depict actual turbulence encounters, two from the NASA B-757 aircraft, and two from documented accident cases of commercial transport aircraft. ${ }^{44,47,50,51}$ A radar simulator, developed for the NASA Predictive Wind Shear System Project, was modified to interface with the four turbulence data sets and hazard table algorithm. A block diagram of this tool is shown in Fig. 25. An automated scoring package was also developed as part of the comparative analysis and statistics element. The resulting capability enables a turbulence prediction algorithm to be tested via simulation of an airplane flight path through known atmospheric turbulence, and the output of the algorithm displayed and scored. This is considered by the FAA and avionics manufacturers to be a minimum performance evaluation capability for airborne radars with turbulence prediction capability. A threeyear project has been initiated by the FAA to further develop E-Turb Radar certification standards and guidance.

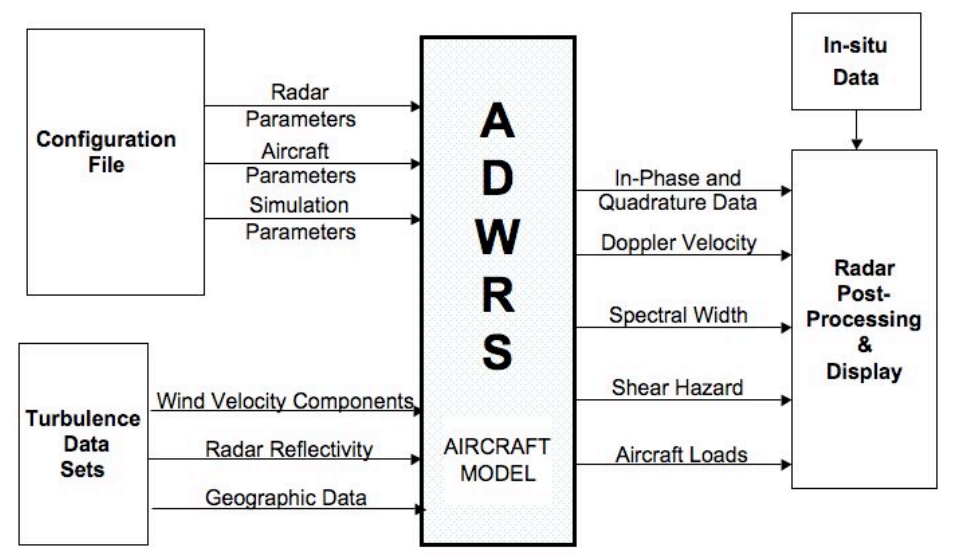

Figure 25. Block diagram of Airborne Doppler Weather Radar Simulator (ADWRS) certification tool.

\section{Airborne Weather Reporting}

A key to safer and more efficient operations is knowing where the hazardous weather is (observations) and where it's going to be in the future (forecasting). Improved forecasting and dissemination of hazardous weather locations enables aircraft operators to strategically avoid atmospheric hazards such as icing, turbulence, and thunderstorms, thus improving aviation safety, efficiency and mobility. Current ground-based and in-situ observations have significant voids in atmospheric observations. Most of the moisture, a key factor in hazardous weather development, is at altitudes below 25,000 ft., and existing observation systems provide few, sparse data in this region. Currently, the Meteorological Data Collection and Reporting System (MDCRS) ${ }^{52}$ collects position, temperature and wind data transmitted to the ground from participating jet transport aircraft via the Aircraft Communications Addressing and Reporting System (ACARS) and sends the information to the U.S. National Weather Service (NWS) for input to forecast models. Because these airplanes operate into and out of only about sixty major airports in the U.S., the atmospheric soundings are limited to these locations. At cruise altitudes, observations are high above most of the adverse weather. A few of these aircraft have also been equipped to report moisture and turbulence data.

Aircraft operating at the lower altitudes and serving smaller airports have the potential to make a significant contribution to improving weather products through the collection and dissemination of in-flight weather observations. Aircraft, such as those operated by regional airlines and package carriers, flying defined routes on a regular basis and capable of operating in instrument meteorological conditions, appear to be the best candidates for airborne weather reporting. There are approximately 1500 regional airline and 500 package carrier aircraft currently operating in the U.S. Business and other GA aircraft could be used to fill remaining voids in weather reporting. Implementation of an automated, in situ, airborne weather reporting system using these airplanes will require viable weather sensors and an extensive data link communication system. 


\section{A. Tropospheric Airborne Meteorological Data Reporting}

NASA has worked with the FAA, NWS, industry, and research community to develop such capabilities for small aircraft. ${ }^{53,54}$ A robust, compact, lightweight, low-cost, integrated sensor system, referred to as a Tropospheric Airborne Meteorological Data Reporting (TAMDAR) sensor, has been developed to automatically measure and report humidity, pressure, temperature, wind, turbulence, icing, and location from aircraft in flight. TAMDAR enables the use of smaller, lower-flying aircraft as airborne sensor platforms to generate in-situ measurements, provides the capability to make observations at all flight altitudes and significantly increases the quality and coverage, both temporal and spatial, of atmospheric observations, thus enabling improvement in the accuracy of hazardous aviation weather identification and its avoidance for safety of flight. The prototype sensor has been evaluated in flight against established atmospheric measurement systems on airplanes operated by the University of North Dakota, NOAA, U. S. Navy and NASA. Communications architectures and technologies have also been developed for distribution of data to the NWS, FSS, and other aircraft in flight. Most recently, Mesaba Airlines' fleet of Saab 340's has been equipped with the TAMDAR system for a twelve-month operational evaluation and

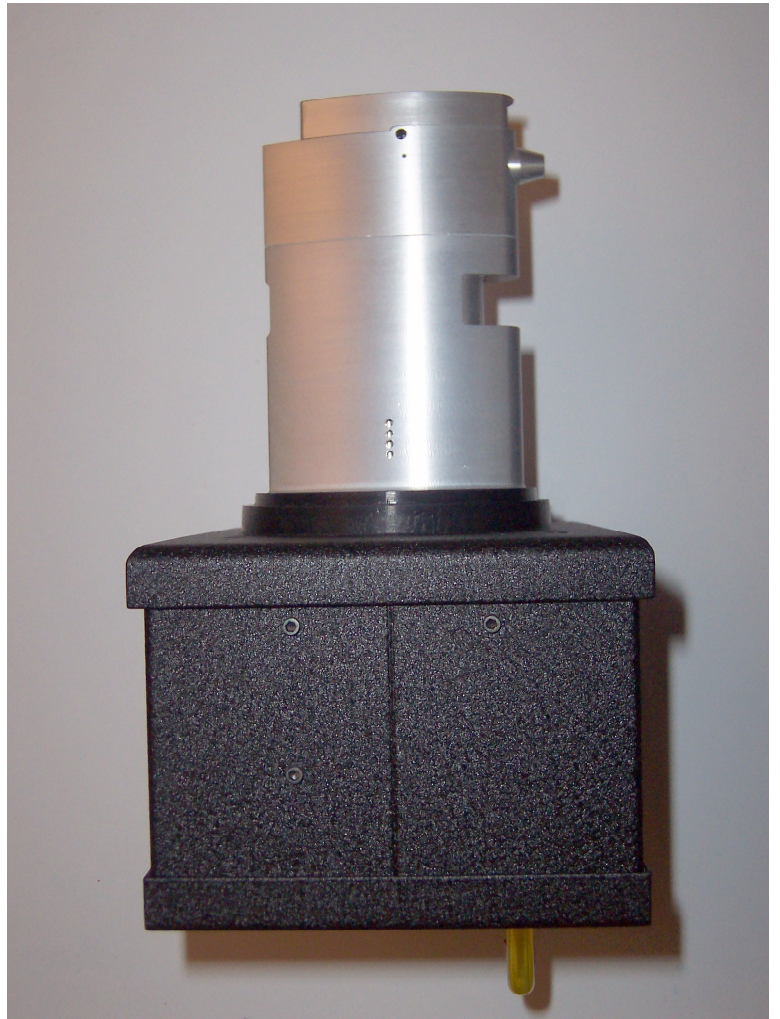

Figure 26. TAMDAR sensor showing probe (top) and signal processing unit (black box at bottom).

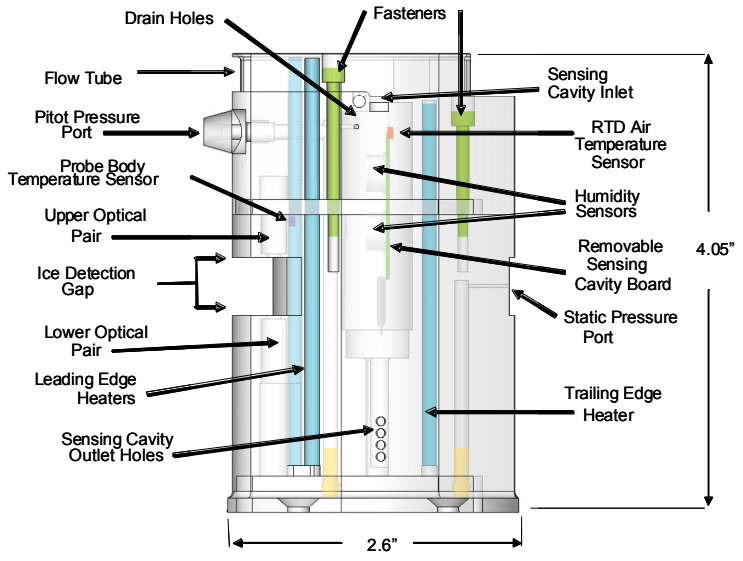

Figure 27. Side cutaway view of TAMDAR sensor body.

scrutiny by the "weather community." The sensor, developed in conjunction with Georgia Tech Research Institute and AirDat, LLC., measures temperature, relative humidity, pressure, and icing. It can compute pressure altitude, indicated airspeed, true airspeed, turbulence and winds. The sensor (Fig. 26) consists of a probe (external to the aircraft) and an attached signal-processing unit. A cutaway view of the probe is shown in Fig. 27.

A dynamic pressure port protruding from the leading edge and a static port located on the trailing edge of the sensor body are connected to a differential pressure transducer located inside the signal processing unit. These pressure measurements are used to compute indicated and true airspeed. An additional algorithm computes eddy dissipation rate (an aircraft independent measure of turbulence) using an implementation of MacCready's method. ${ }^{55}$

A flow tube directs air into a sensing cavity containing a removable printed circuit board equipped with a resistance temperature detector (RTD) air temperature sensor and two relative humidity (RH) sensors. The RH sensors are Hycal 3610-002. Airflow from the sensor cavity is discharged through holes (four on each side) near the base of the sensor.

A leading edge notch incorporates two pairs of infrared (IR) transmitters and detectors (shown as upper and lower optical pairs) for ice detection. Ice accumulation is registered when the outside air temperature is below $10^{\circ} \mathrm{C}$ and both IR beams are blocked ( 0.02 in ice thickness). When ice is detected, the leading and trailing edge heaters are activated to melt the accumulated ice and remain powered for at least one minute. The large electrical current flow 
to the heaters affects the other measurements, so all data are flagged as unusable during deicing. When the ice is removed, the heaters switch off.

A built-in Garmin GPS-15L Global Positioning System provides time, latitude and longitude for each observation and provides the ground track, which is used with externally provided heading information to calculate winds aloft. The signal-processing unit computes derived parameters from basic measurements. These data are then formatted and output from a serial port to a data link transceiver. The algorithms used to process the measured and derived parameters reside on programmable read only memory within the signal-processing unit. This memory chip can be updated with new algorithms, sampling rates, or calibration constants via the data link. In addition to the sensor factory calibrations, a post-aircraft-installation calibration is performed to correct for installation or position dependency of measured parameters. The electrical connections to the aircraft include power for the sensors and signal processor, power for the deicing heating elements, signals to and from a dual GPS/data-link antenna, and an output from the aircraft heading sensor.

\section{B. Observation Protocol}

All observation intervals are based on pressure with a timed default. During take-off, as the aircraft true air speed exceeds 80 knots, the sensor automatically determines departure field pressure. An observation is made every 10 $\mathrm{hPa}(\sim 300 \mathrm{ft})$ for the first $200 \mathrm{hPa}(\sim 6,000 \mathrm{ft})$ of pressure altitude, then every $20 \mathrm{hPa}(\sim 800 \mathrm{ft})$ for all measurements above $200 \mathrm{hPa}(\sim 6,000 \mathrm{ft})$. To avoid constant triggering of observations if the aircraft altitude is "hovering" about a particular threshold point, simple logic is applied before a pressure based observation is triggered. Once a threshold is crossed, crossing that same threshold again will not trigger a new observation unless a higher or lower threshold is crossed first. This observation protocol is a modification of ARINC 620 Version 4, which is being standardized by the World Meteorological Organization (WMO) Aircraft Meteorological Data Relay (AMDAR) Panel. ${ }^{56}$

The time default for observation intervals ensures periodic reports during cruise when there is no significant change in measured ambient pressure. An observation is made after three minutes if the pressure is greater than 465 $\mathrm{hPa}$ (altitude less than $\sim 20,000 \mathrm{ft}$ ), or seven minutes if the pressure is less than $465 \mathrm{hPa}$ (altitude greater than $\sim 20,000 \mathrm{ft}$ ). Special observations are triggered by an icing onset, with a minimum time of one minute between observations due to icing. Reports are transmitted after a specific number of observations are accumulated. If a report has not been transmitted for a default period of fifteen minutes, then a report is transmitted. After transmission, the time is reset and the next report occurs when the next set of observations have been accumulated, or at the end of the default period, whichever comes first. Except for turbulence and icing, observation measurements are low-pass filtered with a frequency cutoff of $0.1 \mathrm{~Hz}$. Peak and median turbulence statistics at the end of a report apply to the total reporting interval. The TAMDAR unit always archives the last ten observations and upon landing, the last ten $10 \mathrm{hPa}$ interval observations are transmitted.

\section{Operational Evaluation}

TAMDAR sensors have been installed on 63 Mesaba Airlines Saab 340 turboprop aircraft (Fig. 28) flying in the Great Lakes region of the U.S. for evaluation in an operational environment. These aircraft make over 400 flights daily to 75 airports, thus providing more than 800 soundings for a total of over 25,000 daily observations in the region shown in Fig. 29. These observations are significant when compared with the approximately 100,000 daily observations of wind and temperature over the entire contiguous U.S. from aircraft that currently provide MDCRS data. This evaluation, referred to as the Great Lakes Fleet Experiment (GLFE), ${ }^{57,58}$ started in January 2005 and runs through January 2006.

TAMDAR data are being evaluated by NOAA through daily use by operational forecasters at NWS forecast offices and by researchers at the Forecast Systems Laboratory (FSL). NWS forecasters generate Area Forecast Discussions and special reports to document cases in which the GLFE data make a notable difference in their forecast decisions. Direct comparisons are being made between wind, temperature and humidity data from TAMDAR and from radiosondes. These comparisons have been facilitated by extra radiosonde

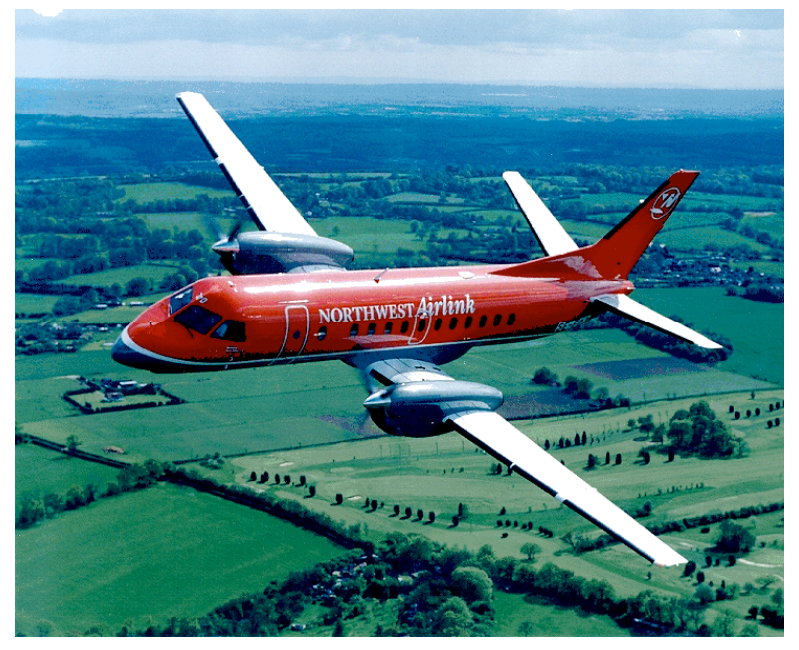

Figure 28. Mesaba Airlines Saab 340. 
launches made at Memphis International Airport by the University of Wisconsin transportable sounding team ${ }^{59}$ during two 2week periods in March and June 2005. In addition to balloon data, the team collected temperature and moisture profiles using the Atmospheric Emitted Radiance Interferometer (AERI), a fully automated ground-based passive infrared sounding instrument. TAMDAR data are also being used for assessment of impact on performance of the Rapid Update Cycle (RUC) aviation weather forecast code. ${ }^{60,61}$ The RUC already assimilates in situ aircraft observations of wind and temperature; however, this will be the first use of aircraft moisture observations. Two identical versions of the RUC will be retrospectively run, one using TAMDAR data and one not. Both models will be run for specific time periods covering a variety of weather events. The forecasts will then be compared with observations from radiosondes and wind

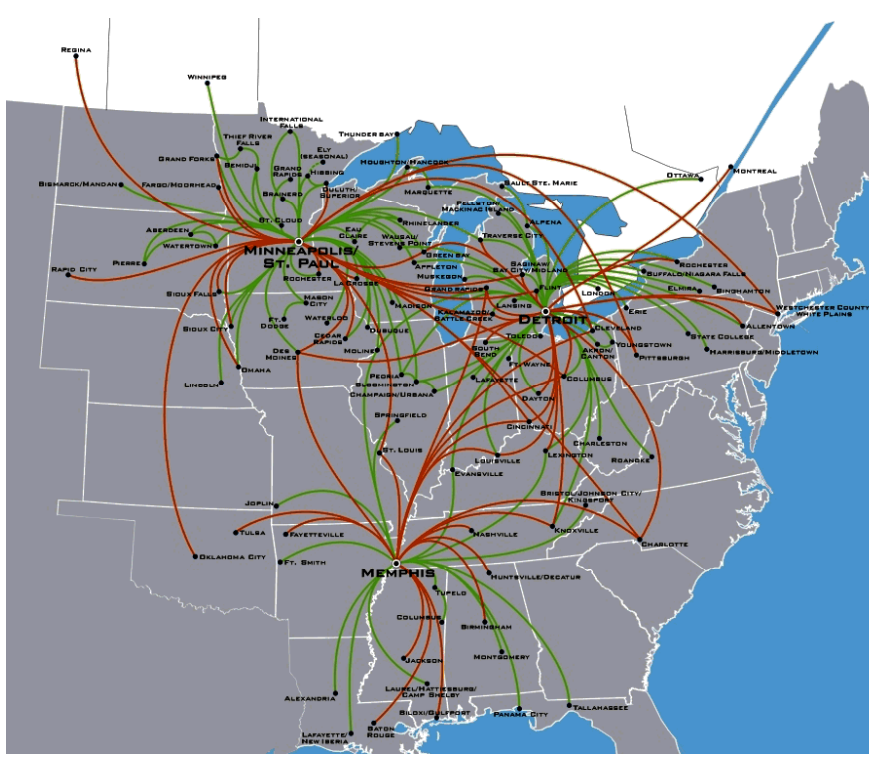

Figure 29. Mesaba Airlines Saab 340 routes. profilers to assess the benefits of incorporating TAMDAR data. During the GLFE, Mesaba pilots are completing PIREP forms for the take-off, cruise, and landing phases of their flights. Among the data annotated by the pilots are time, flight mode, altitude, location, temperature, icing state, cloud tops, turbulence, in/out of cloud, and precipitation type. Within the FAA's Aviation Weather Research Program (AWRP) Quality Assessment Product Development Team, researchers at the National Center for Atmospheric Research (NCAR) are analyzing these reports as part of a Real Time Verification System. ${ }^{62}$ Researchers at NCAR are also evaluating the impact of TAMDAR data on the Current Icing Potential (CIP) algorithm; ${ }^{63}$ the prediction of convective precipitation, shortterm forecasts of convection using the NCAR Thunderstorm auto-nowcast system, ${ }^{64}$ and on precipitation forecast skill. Using the University of North Dakota Cessna Citation atmospheric research airplane, NCAR is performing an evaluation of the TAMDAR implementation of the MacCready turbulence algorithm and compare it with other methods of reporting eddy dissipation rate (EDR) as a measure of turbulence. ${ }^{65}$ All of these studies are scheduled for completion by late fall 2005.

\section{Weather Information Communication}

Weather information communication is the enabling technology that allows the sharing of data and information between the ground and air domains and information transfer between aircraft. Figure 30 depicts the data link development approach used in accomplishing the communications technology improvements to date and the representative communications links. Firstgeneration systems were necessary for early market penetration and proving the value of weather situational awareness to the cockpit and initial acceptance of the aviation weather community. Second-generation systems integrated weather information into upcoming aviation communications and surveillance links due to the acceptance and perceived value of initial systems. Third-generation or future anticipated systems, still to be developed, provided the vision that has guided development to the present time.

Communications requirements and associated data-link architectures optimal for the delivery of graphical weather products to GA and commercial-

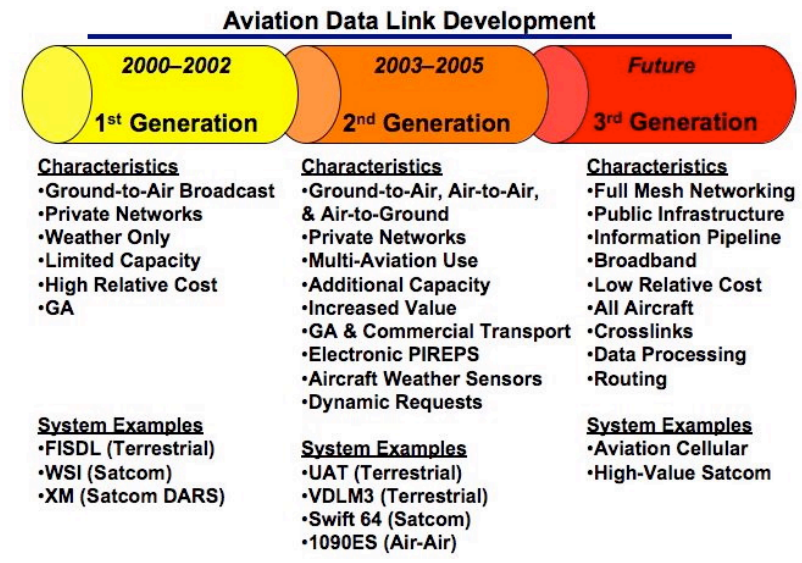

Figure 30. Approach to data link development. 
air-transport cockpits have been investigated. ${ }^{66-68}$ These studies established current, mid-term (2007), and long-term (2015) weather communications needs and resulting requirements. Through a NASA cooperative research agreement with Honeywell International, a VHF Data Link Mode 2 (VDLM2) data link operating in the aeronautical VHF frequency band was demonstrated with broadcast data rates up to $31.5 \mathrm{Kbps}$. Under contract to NASA, ViGYAN developed a satellite-based aviation weather information system known as the Pilot Weather Advisor to broadcast text and graphical weather information to aviation users at any altitude, anywhere in the U.S. NASA also investigated the use of state-of-the-art satellite digital audio radio systems (SDARS) for delivery of weather information. Recently XM Radio and Sirius have begun offering U.S. nationwide compact-disc-quality digital audio radio services to home and automotive subscribers via SDARS commercial satellites. Internationally, WorldSpace has been offering similar services.

NASA, in partnership with WorldSpace and Rockwell Collins, investigated the feasibility of SDARS for FIS transmission to GA aircraft (Fig. 31) in South Africa during September 1999 using the AfriStar SDARS satellite. With excellent performance demonstrated in South Africa, NASA, Rockwell and WorldSpace continued the investigation by partnering with Jeppessen and American Airlines to evaluate the dissemination of graphical weather products to airliners flying oceanic routes between the U.S. and the Pacific Rim. ${ }^{69}$

Early success and stimulation of the market by NASAindustry cooperative research and development efforts from 2000 through 2002 contributed to the development and deployment of first-generation commercial systems including the Honeywell FISDL, WSI InFlight, and XM WX Satellite services. The importance of these systems in the ongoing process of weather dissemination research and development was significant, but was not the end goal. These first- generation systems broadcast a set of weather products to the cockpit from the ground via satellite or terrestrial stations. Due to their one-way nature, ondemand individual pilot requests of weather information beyond the prearranged suite are not supported. Delivery of hazardous weather observations between aircraft or to

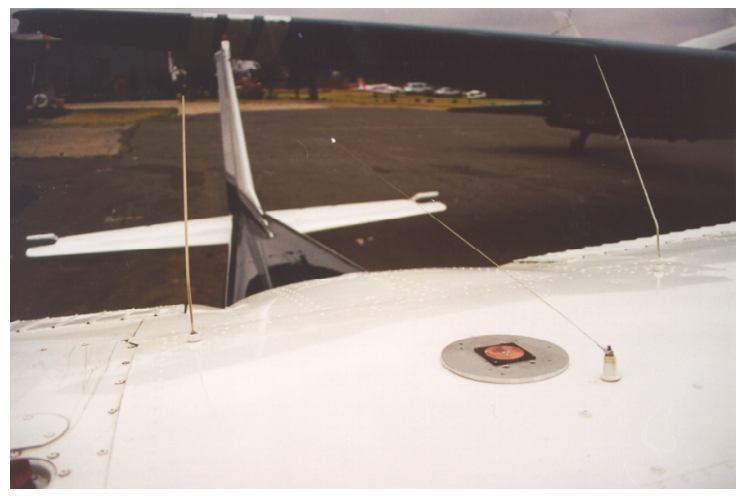

Figure 31. Patch antenna mounted to the top of the fuselage of the Cessna 172 used for flight evaluations of weather data-link capabilities using the AfriStar satellite. the ground was not possible.

Since then, weather dissemination data links for the next, or second, generation systems have been developed, validated by laboratory and flight testing, and recommendations made to the aviation community. These data links encompass the communication domains of ground-to-air, air-to-ground, and air-to-air, including both commercial and government systems. These systems though remain aviation focused, not being shared by a broad diverse user base. Data link capacity was increased with application to a broader user base, GA and commercial, that could reduce equipage cost. Automated in situ weather reporting, event-driven automated turbulence reporting, and dynamic pilot requests are enabled in these second generation systems.

The process of selecting aviation data links to demonstrate dissemination of weather information included concept of operations, communications requirements, candidate architectures, modeling and simulation, current and planned equipage, current use restrictions, policies affecting future data links, and cost of the data links. Aviation data-link architectures were selected based on their ability to disseminate weather information during the en-route phase of flight. This included ground-to-air transmission to the flight deck of graphical and textual weather information, air-to-ground transmission of in situ weather observations, and air-to-air transmission of turbulence hazard information between aircraft. Ground networking was addressed only as it applies to the routing of airbornesensed weather information from ground stations to data collection centers and of weather products from providers to ground stations for transmission to aircraft.

Three distinct operational architectures were addressed based on aircraft class and operational airspace: (1) U.S. national capability for regional and GA operations; (2) U.S. national capability for commercial transport operations; and (3) global capability for transport operations. To be recommended as a viable solution, a data link had to demonstrate (1) transmission and reception of weather information without impacting "normal" traffic and (2) feasibility of an operational implementation. The validation of data links was accomplished through partnerships between NASA, FAA, industry, and academia. 


\section{A. U.S. National Capability for GA and Regional Aircraft}

A weather dissemination capability was developed for GA and regional aircraft within a national network that included (1) ground-to-air reception and display of FIS-B weather products, (2) broadcast of data from an onboard atmospheric sensor to other aircraft and ground users, and (3) reception of atmospheric information transmitted from other airplanes.

The Universal Access Transceiver (UAT) system was selected for development of a GA and regional weather dissemination capability. This link has been selected by the FAA for GA Automated Dependent Surveillance Broadcast (ADS-B) services. The goals of the FAA in encouraging equipage meshed with NASA's needs to provide weather information in all the communication domains for GA over a multi-use link not funded or supported solely by the aviation weather information service providers and users. UAT equipment was modified and utilized to satisfy requirements for ground-to-air broadcast of weather information, air-to-ground delivery of atmospheric data from airborne sensors, and air-to-air reporting of weather hazard information to aircraft within range.

Weather information from the appropriate sources was routed to the Ground Based Server (GBS) via the UAT network hub located at the FAA Technical Center. The Ground Based Terminals (GBT) then transmitted the information to aircraft within range of the stations. Weather data from sensors onboard the aircraft were processed for cockpit display to the pilot and transmission to other aircraft and to the ground. These transmissions provided hazard awareness to pilots of other proximate aircraft and provided weather data to ground-based meteorologists for use to enhance models leading to improved forecasts.

The required data link modifications were limited to the recognition and routing of additional messages not currently in the UAT standard traffic, and did not require a redesign of the UAT message formats and structures. Airborne weather sensor data were inserted into an unused portion of the UAT ADS-B message for transmission. Reception of these data by other aircraft required avionics modifications to enable recognition, extraction and routing of the data to the flight deck display, and display modifications for the presentation of the data. Sensor data reception at the ground required GBT modifications enabling recognition, extraction and routing to the appropriate ground users. Additional weather products were defined enabling recognition and processing of these as valid products at the GBT for transmission, the aircraft avionics for reception, and the aircraft display for presentation.

Avionics recognition and routing of messages received from the ground included the reception of ground-to-air FIS-B weather products. Unmodified UAT equipment was limited to two textual and one graphical weather products, while enhancements allowed a full set of products to be received by modified avionics. Modifications to the avionics also enabled recognition and routing of messages originating onboard for transmission from the aircraft. This consisted of data from onboard atmospheric sensors that were broadcast to other aircraft and ground users. Avionics recognition and routing of similar messages received from other equipped aircraft were also enabled.

Ground station recognition and routing of messages originating from aircraft included information from airborne atmospheric sensor equipped aircraft broadcast to the ground. (Unmodified UAT equipment reception is limited to ADS-B messages.) Ground station recognition and routing of messages received from ground weather information providers included weather products received from multiple sources for inclusion within the FIS-B of the Ground Uplink Message. Modifications allowed a full set of weather products to be broadcast, whereas the unmodified system was limited to two textual and one graphical products.

Laboratory testing involving modified and unmodified (backwards compatibility verification) avionics and ground stations was conducted at the FAA Technical Center in 2004. Flight-testing during the spring of 2005 provided final validation of weather dissemination capabilities. These tests used two NASA Lear Jets equipped with modified avionics and an operational UAT ADS-B station installed at the Cleveland Hopkins International Airport, USA.

\section{B. U.S. National Capability for Commercial Transport Aircraft}

A weather dissemination capability was developed for commercial transport aircraft within a U.S. national network that included (1) ground-to-air reception and display of FIS-B weather products, (2) air-to-ground pilot weather information requests, (3) dissemination of data from own-ship turbulence encounters to other aircraft and ground users, and (4) reception, processing and delivery of turbulence reports from other aircraft to the cockpit.

The FAA Very High Frequency (VHF) Data Link Mode 3 (VDLM3) and 1090 Extended Squitter (ES) ADS-B data links were selected for development of a commercial transport weather dissemination capability.

VDLM3 was utilized for ground-to-air broadcast of weather information and air-to-ground reporting of turbulence encounters. Weather information from the appropriate weather service information center was routed to the VDLM3 ground stations from which it was then broadcast to the aircraft. VDLM3 also accommodated pilot requests for specific weather information not included in the basic broadcast (ground-to-air weather information) 
and the subsequent augmented broadcast containing the requested information for a pre-determined period of time. The VDLM3 ground network provided routing of turbulence reports to the appropriate data collection center.

1090ES satisfied the requirements for air-to-air delivery of turbulence reports to other aircraft. Airborne turbulence reports were broadcast via 1090ES to all aircraft within reception range, limited only by the transmitted power of the sending aircraft and receiver sensitivity of other aircraft. This specific in-situ turbulence encounter information is a limited version of the turbulence reports also sent to the ground via the VDLM3 air-to-ground data link and routed to the appropriate data collection center for generation of U.S. national turbulence reports and forecast products.

Weather information from the ground to aircraft used a broadcast message. Although a VDLM3 ground-to-air broadcast capability exists by design, this mode of communication had not been implemented to date. The required data link modifications included the enabling of Transport Control Protocol/Internet Protocol (TCP/IP) directly over VDLM3 in lieu of the Aeronautical Telecommunications Network (ATN) protocol stack in the Communication Management Unit (CMU) and recognition and routing of messages not currently in the VDLM3 standard planned traffic.

A turbulence encounter message was incorporated within the standard 1090ES message structure. Location, aircraft type, turbulence severity, and other required parameters needed for relevance processing on the receiving aircraft were broadcast directly (air-to-air) between aircraft. Location of the transmitting airplane was obtained from the already transmitted/received ADS-B message to minimize the size of the turbulence message. The 1090ES ground stations (i.e. air-to-ground or ground-to-air) were not used for this or any other weather related message because modeling and simulation had indicated an inadequate capacity.

Laboratory testing with VDLM3 avionics and ground stations and 1090ES avionics was completed in November 2004. Flight-testing providing final validation of VDLM3 weather dissemination capabilities occurred at the FAA Technical Center in the spring of 2005. Flight testing of 1090ES weather dissemination capabilities occurred in spring 2005 utilizing two NASA Lear Jets equipped with modified 1090ES avionics.

\section{Global Capability for Transport Aircraft}

A weather dissemination capability was developed for commercial transport aircraft operating in international and oceanic environs that included (1) ground-to-air reception and display of FIS-B weather products, (2) dissemination of data from own-ship turbulence encounters to other aircraft and ground users, and (3) reception, processing, and delivery of turbulence reports from other aircraft.

The architecture selected for development of an international/oceanic global weather dissemination capability used the SWIFT 64 Multiple Packet Data Service (MPDS) mode via the Inmarsat satellite constellation. Requirements for ground-to-air broadcast of weather information and reporting of turbulence hazards to the ground and other aircraft were satisfied utilizing the SWIFT 64 network service provided by SITA.

Current cockpit communications have focused on circuit switched satellite capabilities, failing to capitalize on the newer services and associated capabilities that packet services could provide in a more cost efficient manner. For the international and oceanic environments, packet based, Inmarsat I3 services and capabilities were selected for the dissemination of weather information. Packet services to date in the cabin have been available only on a best effort basis providing no guarantee to quality, availability or latency of the data required for use by the cockpit.

A test bed emulator of the aircraft environment, including both the cockpit and cabin users, was developed. IP was chosen as the network protocol due to the potential advantages of IP not realizable with ATN. Inmarsat's current thrust is also to transition safety service from ATN to IP in the 2010 time frame. An EMS HSD-128 Inmarsat Aeronautical Terminal provided the satellite interface to the Inmarsat I3 constellation for the testing.

The research focused on evaluating quality of service (QoS) algorithms for seamless on-board separation of packet data services between cockpit and cabin, assuring a higher QoS to the cockpit at most times. The QoS utilized a hybrid approach, located at both the on-board aircraft router and ground station. Three methods were evaluated: priority queuing, class based queuing, and stochastic weighted fairness queuing. Priority queuing divides the traffic into different queues with cockpit traffic placed in a higher queue than cabin traffic. Queues are emptied from highest to lowest priority. The advantage of this method is ease of configuration at the loss of granularity. Class based queuing places traffic into a hierarchal data structure allowing for the same two queues as in priority queuing, but allowing for a second level of queuing to occur between critical and non-critical traffic within each queue. Queues are emptied from highest to lowest priority. The advantage of this method is the finer granularity. Stochastic weighted fair queuing separates traffic into queues with the queues then processed in a round robin fashion based on the pre-defined percentage for each pass of each of the queues. This assures a minimum level of service with every queue serviced, even the lowest. 


\section{Future Weather-Dissemination Data Links}

While there is much interest in network-enabled operations and broad system management of information, there has been little attention given to the development of the physical data links required to bridge diverse aircraft intranetworks and ground networks. Weather dissemination technology progress has been significant but has relied on the innovative use of existing or planned data links. Future data links for weather dissemination should be fullmesh, non-blocking networks as a part of an overall network-enabled operations architecture that supports a true information pipeline. Weather data and information are expected to increase along with other communication demands for a new generation of air traffic control, safety and security functions requiring a broadband link serving all aircraft. Cross-linking capabilities, increased ground and air data processing, and complex/flexible routing schemes must also be addressed in future communications systems. These future capabilities will only be realized if the equipment and services to support the networks and enabling data link are affordable. Broad user-based shared commercial systems, such as true aviation cellular and high value satellite communications, may hold the key to reduction in costs. Without equipage there can be no improvement.

\section{Summary}

Technologies, developed by the National Aeronautics and Space Administration (NASA) in partnership with the Federal Aviation Administration (FAA), National Oceanic and Atmospheric Administration (NOAA), industry and the research community, have been presented for airborne detection, dissemination and display of weather information. First-generation data-link cockpit weather information systems have been implemented, especially by GA operators. A prototype next-generation cockpit weather information system has been developed with the capability to combine information from both on-board sensors and data-links and to display graphical and textual weather information to the pilots, evaluate both tactical and strategic hazards in the weather data stream, and provide alerts. Technologies have been developed to enhance the capability and accuracy of onboard weather radars to detect turbulence and display its severity up to 25 nautical miles ahead of commercial jet transports for altitudes greater than $2000 \mathrm{ft}$ AGL. Automated, event-driven, turbulence encounter reporting using an acceleration-based hazard metric has been developed. Both of these turbulence capabilities have progressed from research aircraft and prototype systems to yearlong in-service evaluations with a major U.S. air carrier, concluding in September 2005. Tropospheric Airborne Meteorological Data Reporting (TAMDAR) capability has been developed to provide automated atmospheric soundings and observations from aircraft in flight for improved aviation weather reporting and forecasting. TAMDAR technologies have been implemented on a fleet of regional airplanes and are midway through a yearlong evaluation by the weather community. Data-link technologies have been developed for first generation systems that enable affordable and reliable broadcast of a set of weather products to the cockpit from the ground via satellite or terrestrial stations. Weather dissemination data links for the next, or second, generation systems have been developed, validated by laboratory and flight testing, and recommendations made to the aviation community.

\section{References}

\footnotetext{
${ }^{1}$ National Aviation Weather Program Council Joint Action Group for Aviation Weather: National Aviation Weather Program Strategic Plan. Office of the Federal Coordinator for Meteorology, FCM-P32-1997, April 1997.

${ }^{2}$ National Aviation Weather Program Council Joint Action Group for Aviation Weather: National Aviation Weather Initiatives. Office of the Federal Coordinator for Meteorology, FCM-P34-1999, February 1999.

${ }^{3}$ Federal Aviation Administration: Safer Skies: Focused Safety Agenda - Weather Joint Safety Implementation Team. Final Report, March 2000.

${ }^{4}$ Huettner, C.: Toward a Safer 21st Century - Aviation Safety Research Baseline and Future Challenges. NP 1997-12-231HQ, 1996.

${ }^{5}$ Wiener, Earl L.; and Nagel, David C. (editors): Human Factors in Aviation. Academic Press, 1998, page 578.

${ }^{6}$ Kauffmann, P.; and Pothanun, K.: Estimating the Rate of Technology Adoption for Cockpit Weather Information Systems. SAE Paper 2000-01-1662, 2000.

${ }^{7}$ Crabill, N. L.; and Dash, E. R.: Pilot Automated Weather Support System (PAWS) Concepts Demonstration Project. DOTFAA-RD-91-9.

${ }^{8}$ Keel, Byron M.; Stancil, Charles E.; Eckert, Clifford A.; Brown, Susan M.; Gimmestad, Gary G.; and Richards, Mark A.: Aviation Weather Information Requirements Study. NASA/CR-2000-210288, June 2000.

${ }^{9}$ Scanlon, Charles H.: A Graphical Weather System Design for NASA Transport Systems Research Vehicle B-737. NASA TM 104205, February 1992.
} 
${ }^{10}$ Scanlon, Charles H.: Cockpit Graphical Weather Information Shown to Enhance Efficiency, Safety, and Situation Awareness. Proceedings of the Flight Safety Foundation 39th Annual Corporate Aviation Safety Seminar, 13-15 April 1994, pp. 83-94.

${ }^{11}$ Kilgore, W.A. et al: Pilot Weather Advisor. NASA SBIR Final Report. NASA Contract NAS1-19250, September 1991.

${ }^{12}$ Shashi, S.; and Crabill, Norman L.: Pilot Weather Advisor. NASA SBIR Final Report. NASA Contract NAS1-19595, December 1994.

${ }^{13}$ FAA News: FAA and Industry Bring Data Link Services to the Cockpit. Federal Aviation Administration, Washington, D.C., APA 85-99, 30 July 1999.

${ }^{14}$ FAA: FAA Announces Operational Flight Information Services Data Link. FAA Press Release APA 08-02, 25 February 2002.

${ }^{15}$ Latorella, Kara; Lane, Suzanne; and Garland, Daniel: General Aviation Pilots' Perceived Usage and Valuation of Aviation Weather Information Sources. NASA TM-2002-211443, February 2002.

${ }^{16}$ Latorella, Kara; Pliske, Rebecca; Hutton, Robert; and Chrenka, Jason: Cognitive Task Analysis of Business Jet Pilots' Weather Flying Behaviors: Preliminary Results. NASA TM-2001-211034, July 2001.

${ }^{17}$ Yuchnovicz, Daniel E.; Burgess, Malcolm A.; Heck, Michael L.; Novacek, Paul F.; and Stokes, Alan F.: Assessment of the Effects of Delayed Weather Information Datalinked to the Cockpit on Pilot Navigation Decision Making. 19th Digital Avionics Systems Conference, October 2000.

${ }^{18}$ Yuchnovicz, Daniel E.; Novacek, Paul F.; Burgess, Malcolm A.; Heck, Michael L.; and Stokes, Alan F.: Use of a DataLinked Weather Information Display and Effects on Pilot Navigation Decision Making in a Piloted Simulation Study. NASA/CR-2001-211047, August 2001.

${ }^{19}$ Novacek, Paul F.; Burgess, Malcolm A.; Heck, Michael L.; and Stokes, Alan F.: The Effect of Ownship Information and NexRad Resolution on Pilot Decision Making in the Use of a Cockpit Weather Information Display. NASA/CR-2001-210845, December 2001.

${ }^{20}$ Beringer, Dennis; and Ball, Jerry: Effects of NEXRAD Graphic Data Resolution and Direct Weather Viewing on Pilot Judgments of Weather Severity and Willingness to Continue Flight. Proceedings of the 47th Annual Meeting of the Human Factors \& Ergonomics Society, Denver, CO, 2003.

${ }^{21}$ Chamberlain, Jim; and Lemos, Katherine: Design Considerations for Presenting Data-Linked Animated Radar Imagery on In-Flight Displays. Proceedings of the 23rd Digital Avionics Systems Conference, Indianapolis, IN, 2004.

${ }^{22}$ Lemos, Katherine; and Chamberlain, Jim: In-Flight Weather Trending Information: Optimal Looping Characteristics for Animated NEXRAD Images. Proceedings of the 23rd Digital Avionics Systems Conference, Indianapolis, IN, 2004.

${ }^{23}$ Latorella, Kara A.; and Chamberlain, James P.: Decision-making in Flight with Different Convective Weather Sources: Preliminary Results. Proceedings of the 11th International Symposium on Aviation Psychology, Ohio State University, Dayton, $\mathrm{OH}, 2001$.

${ }^{24}$ Chamberlain, James P.; and Latorella, Kara A.: Convective Weather Detection by General Aviation Pilots with Conventional and Data-Linked Graphical Weather Information Sources. The 20th Digital Avionics Systems Conference, October 2001.

${ }^{25}$ Latorella, Kara; and Chamberlain, James P.: Graphical Weather Information System: Usability, Perceived Utility, and Preferences from General Aviation Pilots. SAE Paper 2002-01-1521, April 2002.

${ }^{26}$ Burt, Jennifer; Chamberlain, James P.; Jones, Kenneth M.; and Coyne, Joseph T.: The Impact of a Weather Information System Display on General Aviation Pilot Workload and Performance. SAE Paper 2002-01-1522, April 2002.

${ }^{27}$ Horne, Thomas A.: "Weather Links - In-Cockpit Weather Makes Its Debut". AOPA Pilot, April 2002, pp. 101-104.

${ }^{28}$ Kronfeld, Kevin: Enhanced Weather Radar (EWxR) System. NASA/CR-2003-212406, June 2003.

${ }^{29}$ Ruokangas, Corinne C.; and Kelly, Wallace E., III: Advanced Weather Awareness and Reporting Enhancements. NASA/CR-2004-212993, 2004.

${ }^{30}$ Lapis, Mary Beth; Schnell, Tom; and Keller, Mike: Aviation Weather Information Display Study (AWIDS). Georgia Tech Applied Research Corporation, Final Report NASA Contract NAS1-02056 Order No. 6012, October 2004.

${ }^{31}$ Bliss, James P.; Fallon, Corey; Bustamante, Ernesto; Bailey, William R., III; and Anderson, Brittany: Reactions of Air Transport Flight Crews to Displays of Weather During Simulated Flight. Old Dominion University Research Foundation, Final Report NASA Grant No. NAG-1-03061, January 2005.

${ }^{32}$ RTCA, Inc.: Minimum Aviation System Performance Standards (MASPS) for Flight Information Services - Broadcast (FIS-B) Data Link. RTCA/DO-267A, 2004.

${ }^{33}$ FAA: Use of Cockpit Displays of Digital Weather and Operational Information. Advisory Circular AC No: 00-63, 9 September 2004.

${ }^{34}$ FAA: Aeronautical Information Manual 2005. Chapter 7 Safety of Flight, Section 1-11 Meteorology - Flight Information Services Data Link (FISDL), 2004.

${ }^{35}$ Federal Aviation Administration: Guidelines for the Certification, Airworthiness, and Operational Approval of Electronic Flight Bag Computing Devices. Advisory Circular AC No: 120-76A, 17 March 2003.

${ }^{36}$ Boatman, Julie K.: Avionics Market: The Age of Avionics. AOPA Pilot, June 2005, pp. 94-101. 
${ }^{37}$ FAA: Automatic Dependent Surveillance-Broadcast (ADS-B) and Other Broadcast Services - Initial Capabilities in the National Airspace System (NAS). Notice to Airmen, 14 April 2005.

${ }^{38}$ Triplett, William: The Calculators of Calm. Air \& Space Smithsonian, March 2005, pp. 54-61.

${ }^{39}$ Bogue, R.; and Larcher, K.: Aircraft Cabin Turbulence Warning Experiment. $20^{\text {th }}$ International Aircraft Cabin Safety Symposium, 10-13 Feb 2003, Los Angeles, CA.

${ }^{40}$ Kaplan, M.L.; Huffman, A.W.; Lux, K.M.; Charney, J.J.; Riordan, A.J.; and Lin, Y.: Characterizing the Severe Turbulence Environments Associated With Commercial Aviation Accidents---Part I: 44 Case Study Synoptic Observational Analyses. NASA/CR-2002-211918, August 2002.

${ }^{41}$ Hamilton, D.W.; and Proctor, F.H.: Meteorology Associated with Turbulence Encounters during NASA's Fall-2000 Flight Experiments. 40th Aerospace Sciences Meeting \& Exhibit, 14-17 January 2002, Reno, NV, AIAA Paper No. $2002-0943$.

${ }^{42}$ Hamilton, D.W.; and Proctor, F.H.: Convectively-Induced Turbulence Encountered During NASA's Fall-2000 Flight Experiments. 10th Conference on Aviation, Range, and Aerospace Meteorology, 13-16 May 2002, Portland, Oregon, Amer. Meteor. Soc., pp. 371-374.

${ }^{43}$ Proctor, F.H.; Hamilton, D.W.; and Bowles, R.L.: Numerical Study of a Convective Turbulence Encounter. 40th Aerospace Sciences Meeting \& Exhibit, 14-17 January 2002, Reno, NV, AIAA Paper No. 2002-0944.

${ }^{44}$ Proctor, F.H.; Hamilton, D.W.; and Bowles, R.L.: Numerical Simulation of a Convective Turbulence Encounter. Preprints 10th Conference on Aviation, Range, and Aerospace Meteorology, 13-16 May 2002, Portland, Oregon, Amer. Meteor. Soc., pp. 41-44.

${ }^{45}$ Soreide, D.C.; Bogue, R.K.; Bowdle, D.A.; and Hannon, S.M.: Airborne Coherent Lidar for Advanced In-flight Measurements (ACLAIM) - Flight Testing of the Lidar Sensor. 9th Conference on Aviation, Range, and Aerospace Meteorology, 12-16 September 2000, Orlando, FL.

${ }^{46}$ Teets, E, H.; Ashburn, C.; Bogue, R. K.; and Ehernberger, L. J.: Turbulence and Mountain Wave Conditions Observed with an Airborne 2-micron Doppler Lidar. 11th Conference on Aviation, Range, and Aerospace Meteorology, 4-8 October 2004, Hyannis, MA.

${ }^{47}$ Hamilton, D.; Bowles, R.; and Cornman, L.: FY02 TPAWS Radar NASA B757 Flight Campaign Summary. NASA Weather Accident Prevention Project (WxAP) Review [CD-ROM], 20-21 November 2002, Boston, MA.

${ }^{48}$ Hamilton, D.W.; and Proctor, F.H.: An aircraft encounter with turbulence in the vicinity of thunderstorm. 21st AIAA, Applied Aerodynamics Conference, 23-26 June 2003, Orlando, Florida, AIAA Paper No. 2003-4075.

${ }^{49}$ Bowles, R.L.: Turbulence RADAR Hazard Table Development and Implementation. NASA-FAA-Industry Turbulence Certification Workshop \#6, 2-3 December 2003, Hampton, VA.

${ }^{50}$ Lane, T. P., R. Sharman, and T. L. Clark: A Modeling Investigation of Near-Cloud Turbulence. Preprints, 10 th Conference on Aviation, Range, and Aerospace Meteorology, American Meteorological Society, Portland, OR, 13-16 May 2002, pp. 364366.

${ }^{51}$ Proctor, F.; and Hamilton, D.: Certification Methods and Tools. NASA Weather Accident Project (WxAP) Review, 2-4 June 2004, Las Vegas, NV.

${ }^{52}$ Moninger, W.R.; Mamrosh, R.D.; and Pauley, P.M.: Automated Meteorological Reports from Commercial Aircraft. Bulletin of the American Meteorological Society, February 2003, 84, pp. 203-216.

${ }^{53}$ Daniels, Taumi S.: Tropospheric Airborne Meteorological Data Reporting (TAMDAR) Sensor Development. SAE Paper 2002-01-1523, April 2002.

${ }^{54}$ Daniels, T. S.; Tsoucalas, G.; Anderson, M.; Mulally, D.; Moninger, W.; and Mamrosh, R.: Tropospheric Airborne Meteorological Data Reporting (TAMDAR) Sensor Development. 11th Conference on Aviation, Range, and Aerospace Meteorology, Hyannis, MA, American Meteorological Society, October 2004.

${ }^{55}$ MacCready, Paul B., Jr.: Standardization of Gustiness Values from Aircraft. Journal of Applied Meteorology, August 1964, Vol. 3, pp. 439-449.

${ }^{56}$ World Meteorological Organization Aircraft Meteorological Data Relay Panel ARINC-620 Version 4.

${ }^{57}$ Moninger, W. R.; Daniels. T. S.; Mamrosh, R. D.; Barth, M. F.; Benjamin, S. G.; Collander, R. S.; Ewy, L.; Jamison, B. D.; Lipschutz, R. C.; Miller, P. A.; Schwartz, B. E.; Smith, T. L.; and Szoke , E. J.: TAMDAR, The Rapid Update Cycle, and the Great Lakes Fleet Experiment. 11th Conference on Aviation, Range, and Aerospace Meteorology, Hyannis, MA, American Meteorological Society, October 2004.

${ }^{58}$ Mamrosh, R.D.; Brusky, E. S.; Last, J. K.; Moninger, W. R.; and Daniels, T. S.: The TAMDAR Great Lakes Fleet Experiment. Ninth Symposium on Intergrated Observing and Assimilation Systems for the Atmosphere, Oceans, and Land Surface, San Diego, CA, American Meteorological Society, January 2005, paper IOAS-AOLS 5.1.

${ }^{59}$ Feltz, W. F.; Smith, W.L.; Knuteson, R.O.; Revercomb, H.E.; Woolf, H.M.; and Howell,H.B.: Meteorological Applications of Temperature and Water Vapor Retrievals from the Ground-Based Atmospheric Emitted Radiance Interferometer (AERI). Journal of Applied Meteorology, Vol. 37, No. 9, 1998, pp. 857-875.

${ }^{60}$ Benjamin, S.; Bleck, R.; Brown, J.; Brundage, K.; Devenyi, D.; Grell, G.; Kim, D; Manikin, G.; Schwartz, B.; Smirnova, T.; Smith, T; and Weygandt, S.: Mesoscale Weather Prediction with the RUC Hybrid Isentropic-sigma Coordinate Model and Data Assimilation System. Symposium on 50th Anniversary of Operational Numerical Weather Prediction, College Park, MD, American Meteorological Society, 2004. 
${ }^{61}$ Benjamin, S., Brewster, K.A.; Brummer, R.L.; Jewett, B.F.; Schlatter, T.W.; Smith, T.L.; and Stamus, P.A.: An Isentropic Three-hourly Data Assimilation System Using ACARS Aircraft Observations. Monthly Weather Review, 1991, 119, pp. 888906.

${ }^{62}$ Mahoney, J. L.; Henderson, J.K.; Brown, B.G.; Hart, J.E.; Loughe, A.; Fischer, C.; and Sigren, B.: The Real-Time Verification System (RTVS) and its Application to Aviation Weather Forecast. 10th Conference on Aviation, Range, and Aerospace Meteorology, 13-16 May 2002, Portland, OR.

${ }^{63}$ Bernstein, B.C.; McDonough, F.; Politovich, M.K.; Brown, B.G.; Ratvasky, T.P.; Miller, D.R.; Wolff, C.A.; and Cunning, G.: Current Icing Potential (CIP): Algorithm Description and Comparison with Aircraft Observations. Journal of Applied Meteorology, in press 2005

${ }^{64}$ Theriault, K.E.; Wolfson, M.M.; Forman, B.E.; Hallowell, R.G.; Moore, M.P.; and Johnson, R.J., Jr.: FAA Terminal Convective Weather Forecast Algorithm Assessment. 9th Conference on Aviation, Range, and Aerospace Meteorology, 11-15 September 2000, Orlando, Florida.

${ }^{65}$ Cornman, L.B.; Morse, C.S.; and Cunning, J.: Real-time Estimation of Atmospheric Turbulence Severity from In-situ Aircraft Measurements. Journal of Aircraft, Vol. 32 (1),1995, pp. 171-177.

${ }^{66}$ Lockheed Martin Aeronautical Systems, AvCS, Inc.: Data Communications Requirements, Technology and Solutions for Aviation Weather Information Systems, Phase I Report - Aviation Weather Communications Requirements. NASA Contract N66001-97-C-8605, March 1999.

${ }^{67}$ TRW, ARINC, and SAIC: Communications System Architecture Development for Air Traffic Management \& Aviation Weather Information Dissemination - AWIN 2007 Architecture. Contract NAS2-98002, 2000.

${ }^{68}$ Tanger, Thomas; FAA FIS Data Link Assessment and Recommendations. Draft Version 1.0, NASA Internal Report, December 2001.

${ }^{69}$ Kerczewski, Robert J.; and Haendel, Richard: Using Global Satellite Digital Audio Radio Systems for Aviation Weather Dissemination. SAE Paper 2002-01-1530, April 2002. 